\title{
ALOE STRIATA PLANT DEFENSE COMPOUNDS PRODUCED IN RESPONSE TO JASMONIC ACID, SALICYLIC ACID, AND ERIOPHYID MITE SALIVARY EXTRACT ELICITOR COMPOUNDS
}

\author{
A Thesis \\ presented to \\ the Faculty of California Polytechnic State University, \\ San Luis Obispo
}

\author{
In Partial Fulfillment \\ of the Requirement for the Degree \\ Master of Science in Agriculture \\ with Specialization in Plant Protection Science
}

by

Fritz Light

June 2012 
(C) 2012

Fritz Light 
ALL RIGHTS RESERVED 
TITLE:

AUTHOR:

DATE SUBMITTED:

COMMITTEE CHAIR:

COMMITTEE MEMBER:

COMMITTEE MEMBER:
Aloe striata Haworth Plant Defense Compounds Produced in Response to Jasmonic Acid, Salicylic Acid, and Eriophyid Mite Salivary Extract Elicitor Compounds

Fritz Light

June, 2012
Dr. J. Wyatt Brown, Professor, Horticulture and Crop Sciences

Dr. Margaret S. Rice, Professor, Biochemistry

Dr. Michael A. Yoshimura, Professor, Biological Sciences 


\begin{abstract}
ALOE STRIATA HAWORTH PLANT DEFENSE COMPOUNDS PRODUCED IN

RESPONSE TO SALICYLIC ACID, JASMONIC ACID, AND ERIOPHYID MITE SALIVARY EXTRACT ELICITOR COMPOUNDS
\end{abstract}

\author{
Fritz Light
}

\begin{abstract}
Aloe mites are herbivores of the genus Aloe and are associated with hyperplastic growth in various aloe species, but the biochemistry of this interaction is poorly understood. In an effort to characterize plant defense responses to herbivory in the genus Aloe, a salivary extract was isolated from aloe mites (Aceria aloinis Keifer) and its bioactivity was tested using a hypocotyl elongation assay. Subsequently, Aloe striata plants were treated with jasmonic acid (JA), salicylic acid (SA), and the mite salivary extract. Using water and methanol, compounds of different polarity were extracted from aloe tissues that had been frozen and crushed at 4,12 , and $24 \mathrm{~h}$ after treatment. Extracts were analyzed by HPLC and three compounds were found. One of these compounds was SA (mean concentration of $4 \mu \mathrm{g} / \mathrm{mL}$ ), and this is the first time that an aloe species has been found to produce SA. Two additional peaks of unknown identity were observed in JA- and SA-treated plants. These results suggest that $A$. striata may in fact undergo a JAmediated change in secondary metabolism as part of a plant defense response.
\end{abstract}

Keywords: Aloe striata, salicylic acid, jasmonic acid, eriophyid mites, aloe mites, plant defense, elicitors, salivary extract, HAMPs 


\section{ACKNOWLEDGMENTS}

I would like to thank my thesis advisor, Dr. Peggy Rice, for her dedication, constant support, knowledge, sense of humor, and patience - without her, this thesis would not have been possible. I would like to also thank committee members: Dr. Wyatt Brown, for his willingness to chair my committee and for the use of his lab and HPLC system; and Dr. Michael Yoshimura, for the use of his lab facilities and for introducing me to the amazing world of plant pathology.

The stellar tag-team of consulting statisticians: Dr. Jeff Sklar, Dr. John Walker, Dr. Karen McGaughey, Dr. Andrew Schaffner, and Dr. Steven Rein - in the Cal Poly Statistics Department - were essential to the statistical analysis of my data sets. For their effort, I am especially thankful and greatly indebted.

Numerous Cal Poly professors, faculty, and staff in the Biological Sciences (COSAM) and Horticulture and Crop Sciences (CAFES) departments provided me with great service and assistance during my long journey to the completion of this research effort, and I am very thankful to them for their service. Dr. Matt Ritter and Dr. Scott Steinmaus provided me with the space and facilities to grow and house my research plants, in addition to the opportunities and knowledge in plant physiology and botany that were central to this research. Dr. Robert P. Rice, Dr. Michael Costello, and Dr. David Headrick played important early roles in the development of my research, including consultation, education, work opportunities, and general exposure to the exciting realm of plant-pest interactions. 
In the College of Agriculture, Food, and Earth Sciences' Dean's Office, I owe a special thank you to Melanie Gutierrez for her administrative assistance, and, most importantly, to Dr. Mark Shelton, Associate Dean, for his encouragement and his ability to show me clarity during my times of confusion.

I am grateful to Dr. Brian Kemble, Vice President of the Institute for Aloe Studies, for providing me with clean, reliable Aloe striata seeds of known lineage, and I am particularly thankful to the staff, food, and exceedingly comfortable space at Kreuzberg, CA, where a large portion of this research was processed and synthesized into written words.

My friends have been invaluable to the completion of this thesis as well. Brendan Eberhardt, Christian Rojas, Nestor Gutierrez, Emmanuel Solorio, and Soquel Schafer have all assisted me in one way or another with different aspects of the research upon which this thesis is based. They also provided me with fun, laughter, and refuge from the difficult times in my research. My friends David Goldfarb, Mark Krist, and Brandon Nelson provided me with inspiration during the positive times.

I thank my family for all of their love and support; in particular, Sabrina Light, Aaron Light, and my brothers, Jussi Light and John Reth, for their youthfulness, joy, wisdom, soulfulness, encouragement, and musical and comic relief throughout this endeavor. I also thank my mother, Sallie Light, and my grandfather, Robert R. Gerhart, Jr., for their unwavering love, positivity, enthusiasm, and financial help.

Lastly, I thank my father, John Light, whose absence I miss sorely. I would not have had the wherewithal to complete such an undertaking without the positive attributes that he and my mother provided me by giving me life. 
Publication Acknowledgment: We gratefully acknowledge the assistance of Dr. Jeff Sklar, Dr. John Walker, Dr. Karen McGaughey, Dr. Andrew Schaffner, and Dr. Steven Rein in the Cal Poly Statistics Department. 


\section{TABLE OF CONTENTS}

\section{Page}

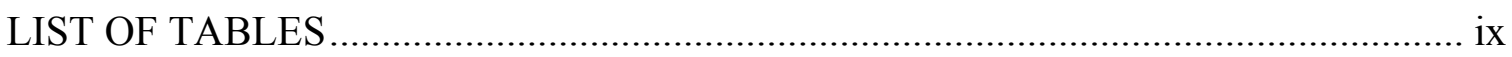

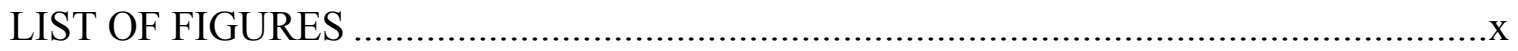

CHAPTER

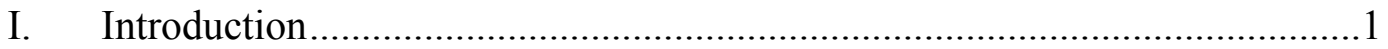

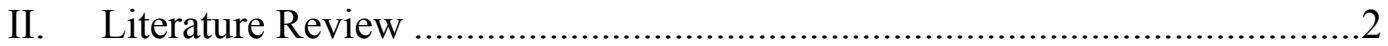

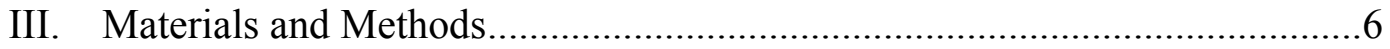

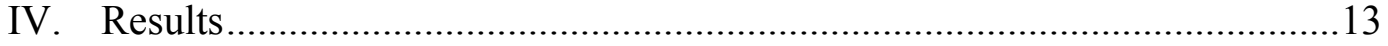

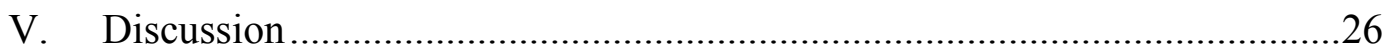

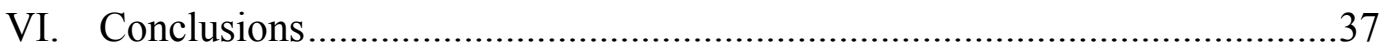

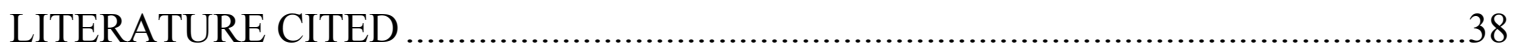




\section{TABLES}

$\underline{\text { Page }}$

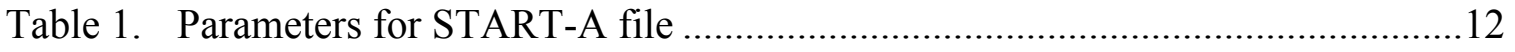

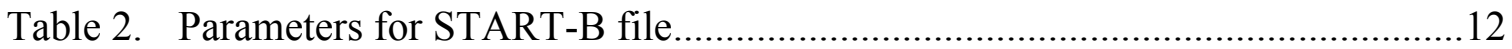

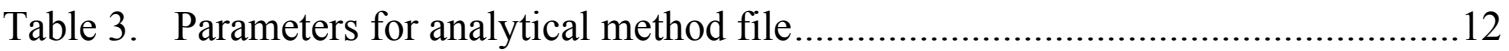

Table 4. Change in zucchini hypocotyl length over a $24 \mathrm{~h}$ period for replicate $1 \ldots \ldots . . . . .14$

Table 5. Change in zucchini hypocotyl length over a $24 \mathrm{~h}$ period for replicate $2 \ldots \ldots \ldots . . .16$ 


\section{FIGURES}

$\underline{\text { Page }}$

Fig. 1. The change in zucchini hypocotyl length in response to IAA, salivary extract, and buffer control over a $24 \mathrm{~h}$ period for replicate 1

Fig. 2. The change in zucchini hypocotyl length in response to IAA, salivary extract, and buffer control over a $24 \mathrm{~h}$ period for replicate 2

Fig. 3. An example of a spectrum max plot comparison between one biological replicate (BR; five red lines) and its corresponding control replicate (CR; five blue lines)

Fig. 4. An example of the spectrum max plot comparison of one unique peak between a biological replicate (BR) (red lines) and its corresponding control replicate (CR) (blue lines)

Fig. 5. Mean PAs of treated plants and controls for Peak A

Fig. 6. Standard curve for salicylic acid produced using HPLC

Fig. 7. Mean PAs of treated plants and controls for Peak B without respect to time......23

Fig. 8. Mean PAs of treated plants and control plants for Peak C

Fig. 9. Mean PAs of treated plants and control plants for Peak D .25 


\section{INTRODUCTION}

Defense responses are commonly found in all flowering plants. It is well known that plants respond to herbivory and pathogeny with both constitutive and induced defense responses (Gozzo, 2003; Kawazu et al., 2012; Erb et al., 2012).

Jasmonic acid and salicylic acid are central to plant immunity. During plant defense responses, SA functions primarily as an internal defense signal which is associated most closely with biotrophic pathogen infection (Leon-Reyes et al., 2009). Jasmonic acid has a wide variety of functions (Wasternack, 2007), acting as a volatile external defense signal for other plants (Ozawa, et al., 2008; Mumm and Dicke, 2010) and as a principal mediator in a variety of plant defense responses (Farmer, 2007; Truman et al., 2007; Agrawal, 2011).

One common physical plant defense response is hyperplastic growth, which often manifests as galls, nodules, cankers, leaf curls, scabs, and witches' brooms (Agrios, 2004). Hyperplastic growth is associated with numerous eriophyid mite species (Oldfield, 1996, 2005).

In the present study, salivary extract from aloe mites was chosen as an experimental treatment because of the possible existence of plant growth promoting substances in such exudations (de Lillo and Monfreda, 2004). The ultimate goal of this investigation was to observe whether Aloe striata Haworth plants produced unique chemical compounds when treated with one putative and two known plant-defense elicitor compounds. 


\section{LITERATURE REVIEW}

Defense responses are commonly found in all flowering plants. It is well known that plants respond to herbivory and pathogeny with both constitutive and induced defense responses (Gozzo, 2003; Kawazu et al., 2012; Erb et al., 2012). Many plants produce compounds to ward off insects and bacterial and viral pathogens, including signaling compounds such as jasmonic acid (JA), salicylic acid (SA), peptides, and direct defense compounds such as glucosinolates (Constabel, 1999; Heil, 2009; Wu and Baldwin, 2009).

Jasmonic acid and SA are central to plant immunity. During plant defense responses, SA functions primarily as an internal defense signal which is associated most closely with biotrophic pathogen infection (Leon-Reyes et al., 2009). The SA pathway is regarded as largely independent of other defense signal transduction pathways (Erb et al., 2012), and it can antagonize the JA signaling pathway (Glazebrook, 2005; Koornneef et al., 2008).

Jasmonic acid has a wide variety of functions (Wasternack, 2007), acting as a volatile external defense signal for other plants (Ozawa, et al., 2008; Mumm and Dicke, 2010) and as a principal mediator in a variety of plant defense responses (Farmer, 2007; Truman et al., 2007; Agrawal, 2011). Jasmonic acid is central to the integration of harmful stimuli perceived by plants into downstream plant defense signals and metabolic changes in response to pathogens and mechanical damage (Glazebrook, 2005; Ballaré, 2011).

Initiation of SA- and JA-related defense responses is mediated by a family of pattern recognition receptors (PRRs) (de Wit, 2007; Schmelz et al., 2006, 2009; Zarate et al., 
2007). Compounds released by pathogens (MAMPs and PAMPs) are known to interact with PRRs (Zipfel, 2006, 2008; Schmelz et al., 2009), and emerging evidence shows that herbivores produce similar compounds that have been designated HAMPs (Felton and Tumlinson, 2008; Heil, 2009; Kim et al., 2012).

A few HAMPs have been isolated and their structures elucidated (Halitschke et al., 2001; Mithöfer and Boland, 2008), but HAMP pattern recognition receptors have not yet been identified in plants (Heil, 2009). Recent literature suggests that plant perception of HAMPs induces regulatory responses that are closely associated with plant growthpromoting hormones such as cytokinins, auxin, abscisic acid, and gibberellins (Erb et al., 2012). Multiple pathways interact to promote plant health in the face of attack (Howe and Jander, 2008; Leon-Reyes et al., 2009).

In contrast, specific pathogen-plant host defense responses are produced in part by pathogen-released substances (elicitors) (Schäfer et al., 2011; Yamaguchi and Huffaker, 2011) that interact with R-genes (Takahashi et al., 2004) in a typical gene-for-gene, coevolutionary relationship (Boller and Felix, 2009). The initial phase of this response is not well understood for herbivores (Boller and He, 2009), however the downstream signal transduction events are similar in both the general and specific responses (Mithofer, 2008). The precise roles of growth hormones such as auxins, cytokinins, gibberellins, abscissic acid, and brassinosteroids in these responses are presently being elucidated (Erb et al., 2012).

One common physical plant defense response is hyperplastic growth, which often manifests as galls, nodules, cankers, leaf curls, scabs, and witches' brooms (Agrios, 2004). Hyperplastic growth is associated with numerous eriophyid mite species 
(Oldfield, 1996, 2005), and these mites exhibit high plant-host specificity (Petanović and Kielkiewicz, 2010; Skoracka et al., 2010). Various species in the genus Aloe (Aloaceae) experience hyperplastic growth known as aloe cancer (Denmark and Keifer, 1979; Meyer and Craemer, 1999; Deinhart, 2011), and there are countless anecdotal reports of the correlation between this proliferative cellular growth and the presence of the herbivorous aloe mite, Aceria aloinis Keifer (Acari: Eriophyidae) (K. Griffin, personal communication, January 13, 2006).

Aloe mites have been observed in exclusive associations with numerous Aloe and Haworthia species (Denmark and Keifer, 1979; Meyer, 1996), which are very closely related (Treutlein et al., 2003; Grace et al., 2009). However, studies specific to aloe mite are scarce (Bethke, 2010), and few scientific investigations of the correlation between aloe mite and hyperplastic growth in aloe plants exist (Meyer, 1996).

One biochemical way to study the effects of aloe mite herbivory on aloes is to isolate salivary extracts, a process used with numerous eriophyid species (de Lillo and Monfreda, 2004). Specifically, elicitor compounds have been isolated from Aceria cauloba saliva (Petanović and Kielkiewicz, 2010).

Jasmonic acid and SA are ubiquitous molecules that perform a great many functions related to plant inducible defense: the integration of harmful stimulus signals (both within and among plants), and the mediation of ensuing downstream metabolic changes. Most of the defense-related processes governed by JA and SA are elicited by attackerreleased substances that interact with specific pattern recognition receptors (PRRs) in plants. Few biochemical interactions between arthropod-related elicitors (HAMPs) and PRRs have been characterized; however, recent evidence links HAMP perception in 
plants with regulatory responses that are closely associated with phytohormones.

Hyperplastic plant growth is associated with growth regulatory hormones and has been frequently observed on aloe plants infested with herbivorous aloe mites. It may be possible that salivary extracts of feeding aloe mites induce hyperplastic growth in aloes as a plant defense response. Investigations regarding this plant-pest interaction, however, are very scarce. 


\section{MATERIALS AND METHODS}

\section{$\underline{\text { Rearing of Aloe striata Plants }}$}

Aloe striata Haworth seeds were obtained from Brian Kemble, curator at the Ruth Bancroft Garden in Walnut Creek, CA.

DryStall pumice (KAT Co., San Clemente, CA) was sterilized to facilitate seed germination. Several cubic feet of the pumice were lightly moistened, placed in aluminum pans, covered, and pressure sterilized in an autoclave for 45 minutes at $122^{\circ} \mathrm{C}$.

To eliminate pathogens, seeds were surface sterilized by immersion in a solution of $10 \%$ sodium hypochlorite for 5 minutes. After treatment, the seeds were fully rinsed with de-ionize (DI) water. The rinse procedure was repeated 50 times, using cheesecloth to retain the seeds. Rinsed seeds were placed between two pieces of Whatman grade 40 filter paper (GE Healthcare Life Sciences, Piscataway, NJ) and light hand pressure was applied to absorb excess moisture.

Bleach-sterilized plastic flats were filled with sterilized pumice, watered with DI water, and allowed to drain to field capacity. Approximately $0.50 \mathrm{~g}$ (180 seeds) were sprinkled evenly across the surface of the pumice-filled flats. A thin layer of pumice was sprinkled over the seed trays and sprayed lightly with DI water. Trays were placed in a growth chamber (Conviron, Winnipeg, Manitoba) with two 24-inch Sylvania Octron ECO 4100K 17-watt Fluorescent Lamps (Osram Sylvania Inc., Danvers, MA) located $75 \mathrm{~mm}$ above the soil surface. The photoperiod was set at 14 hours and the temperature varied between $21^{\circ} \mathrm{C}$ when dark and $25^{\circ} \mathrm{C}$ when lit, for six weeks. Seeds were bottomwatered and misted liberally with DI water daily. 
Twelve weeks after sowing, juvenile aloe plants were individually potted into $6.4 \mathrm{~cm}$ square plastic pots (Kord Products, Toronto, ONT) using a sterilized 1:1 potting mix of pumice and FoxFarm Ocean Forest Natural and Organic Potting Soil (FoxFarm Soil and Fertilizer Company, Samoa, CA). Plants of similar vigor possessing two true leaves of similar length, width, and girth were visually selected and 8 flats were filled with 32 plants each. Flats were returned to the growth chamber and the temperature was adjusted to a constant $25^{\circ} \mathrm{C}$. Photoperiod was maintained at $14 \mathrm{~h}$.

\section{$\underline{\text { Aloe Mite Salivary Extract Processing and Hypocotyl Elongation Assay }}$}

Deformed leaves, inflorescences, and galls were harvested from mature Aloe striata Haw., A. buhrii Lavranos, and A. arborescens Mill. 'Spineless' plants growing in Oceanside, CA. The plant material was stored in open plastic bags in a greenhouse maintained at $20-30^{\circ} \mathrm{C}$ for 1 week until mite extraction.

Aloe mites were extracted in a procedure modified from Monfreda et al. (2007). Deformed plant material was chopped and diced several times to expose the mites and placed in a glass bottle. Approximately $350 \mathrm{~mL}$ of a $0.2 \%$ Tween $80,1.0 \%$ sodium hypochlorite, and $\mathrm{DI}_{2} \mathrm{O}$ extraction solution was added. The bottle was hand-shaken vigorously for 5-10 seconds. The mites were collected by pouring the suspension through a column of USA standard brass testing sieves (Thermo Fisher Scientific, Waltham, MA) in the following configuration (top to bottom): no. 4 (4.75 mm mesh size), no. $10(1.70 \mathrm{~mm})$, no. $28(600 \mu \mathrm{m})$, no. $35(425 \mu \mathrm{m})$, and no. $100(150 \mu \mathrm{m})$. The collected extraction solution was centrifuged for $2 \mathrm{~min}$. at $1800 \mathrm{x}$ g, after which the 
pelletized mites were transferred to a Buchner funnel and excess liquid was strained through Whatman 1 filter paper.

Mite salivary extracts were obtained using a procedure modified from de Lillo and Monfreda (2004). Filter papers with mites were placed in beakers, submerged under a thin volume of immersion oil (Hitachi High-Technologies Corp., Tokyo), and left to incubate at room temperature for approximately 90 minutes. An amount of $0.1 \mathrm{M}$ sodium phosphate buffer $(\mathrm{pH} 6.0)$ roughly equal to the volume of immersion oil was added to each beaker and the mixture was stirred on a magnetic stir plate until a thick emulsion was formed. The emulsion was transferred and centrifuged at 4,600 $\mathrm{xg}$ for five minutes, after which the water fraction was removed and stored at $-80^{\circ} \mathrm{C}$. The extract was freezedried using a Freezone 4.5 lyophilizer (Labconco Corp., Kansas City, MO) over a 24h period. A small volume (1-2 $\mathrm{mL})$ of $0.1 \mathrm{M}$ sodium phosphate extraction buffer was used to re-suspend the extracted compounds before use. Three salivary extractions were performed, resulting in three unique extract solutions (A, B, and C).

Approximately 80 ‘Black Beauty’ zucchini seeds were surface-sterilized by immersion in a 5\% sodium hypochlorite solution for five minutes, then rinsed 50 times with DI water. Groups of 15-20 seeds were placed in separate Phytatrays ${ }^{\mathrm{TM}}$ (SigmaAldrich Corp., St. Louis, MO) lined with unbleached KimTowels (Kimberly-Clark Corp., Dallas, TX). The moist Phytatrays ${ }^{\mathrm{TM}}$ were placed in a Conviron plant incubator set at $25^{\circ} \mathrm{C}$ with a $12 \mathrm{~h}$ photoperiod, and incubated for one week until seeds germinated and hypocotyl length measured approximately $4 \mathrm{~cm}$.

Five petri plates containing $10 \mathrm{~mL}$ of MES buffer $(1 \% \mathrm{w} / \mathrm{v}$ sucrose, $5 \mathrm{mM}$ $\mathrm{MES} / \mathrm{KOH}, \mathrm{pH}$ 6.0) were designated for hypocotyl elongation assays. One plate served 
as the control. Indole acetic acid (IAA) was added to one of the plates to yield a $10^{-4} \mathrm{M}$ IAA solution. The remaining three plates received a $250 \mu \mathrm{L}$ aliquot of mite salivary extract $\mathrm{A}, \mathrm{B}$, or $\mathrm{C}$. This resulted in 5 petri plates for the assay designated: control, IAA, Extract A, Extract B, Extract C.

Hypocotyl segments $1 \mathrm{~cm}$ in length were excised immediately below the cotyledons of 30 robust zucchini seedlings. Each of the five petri plates received six segments and were shaken on an orbit rotary shaker at $100 \mathrm{rpm}$ for $24 \mathrm{~h}$. Hypocotyls were photocopied at a $100 \%$ copy ratio at $0,2,4,8,12$, and $24 \mathrm{~h}$. Hypocotyl lengths were measured from the photocopies.

\section{Aloe striata Biochemical Defense Response Assay}

Ten weeks prior to treatment application, the dark portion of the aloe plants' photoperiod was shifted such that "night-time" stomatal opening coincided with convenient daytime hours for experimentation. Photoperiod duration was not altered. One day prior to treatment application, aloe plants were transferred under dark conditions into double-bagged heavy black plastic garbage bags and placed in a darkened lab to minimize exposure of plants to ambient light.

Solutions of $0.05 \%$ salicylic acid and $0.01 \%$ jasmonic acid were prepared, each in $100 \mathrm{~mL}$ of nanopurified water (18 M $\Omega$ ) obtained from a Barnstead Nanopure Diamond ultrapure water purification system (Thermo Fisher Scientific, Inc., Waltham, MA). The solutions were poured into two separate spray bottles. A third spray bottle was filled with nanopurified water, and an aliquot of approximately $2-5 \mathrm{~mL}$ of previously lyophilized and frozen $\left(-80^{\circ} \mathrm{C}\right)$ mite salivary extract was thawed. Based on the results of the 
hypocotyl elongation assays, salivary extracts A and B were discarded and extract C was chosen for use in all aloe biochemical defense response assays.

Using a random sequence generator, each plant from a group of 65 A. striata plants was randomly assigned to a treatment. The experimental design was a $3 \mathrm{X} 4$ factorial with 5 replicates. Plants were analyzed 4, 12 or $24 \mathrm{~h}$ after treatment and plants were subjected to JA, SA, mite saliva extract, or nanopurified water (control). One set of five completely untreated plants represented an additional control group. Sets of fifteen plants (five plants per time interval per treatment) were then placed into double-bagged black garbage bags for each treatment.

Under darkened lab conditions, each set of 15 plants was treated with either SA, JA, salivary extract, or water. Each plant treated with SA, JA, or water received 4-5 individual mist sprays of the treatment, while each plant treated with salivary extract received 4-5 gentle perforations per plant from a 26-gauge tuberculin needle that was first dipped into the extract.

At the appropriate time $(0,4,12$, and $24 \mathrm{~h})$, the roots were removed from the five plants in a group and discarded, and each remaining plant was weighed, then placed in liquid nitrogen and flash frozen. When thoroughly frozen and brittle, each plant was ground to a fine powder with a mortar and pestle. A $0.5 \mathrm{~g}$ sample of each crushed plant was stored at $-80^{\circ} \mathrm{C}$.

Chemical extraction of aloe compounds was performed on all plants. Previously crushed and frozen plant samples were thawed and $0.5 \mathrm{~mL}$ of nanopurified water was pipetted onto each $0.5 \mathrm{~g}$ plant sample. Each sample was vortexed for five seconds and then centrifuged at $14,000 \mathrm{x} g$ for 20 minutes. The supernatant was separated from its 
pellet and passed through a $0.45 \mu \mathrm{m}, 13 \mathrm{~mm}$ dia. nylon-membrane syringe filter (Thermo Fisher Scientific, Waltham, MA) into an HPLC vial. Subsequently, each of the pellets was extracted using methanol as the solvent per using procedure described above, as numerous previously discovered plant defense peptides are known to be soluble in methanol (Simonsen et al, 2005; Franco, 2011). All samples were stored at $-80^{\circ} \mathrm{C}$ until HPLC analysis was conducted.

\section{HPLC Analysis of Aloe striata Biochemical Defense Response Assay}

HPLC analysis of $A$. striata plant extracts was performed using a Shimadzu Prominence HPLC system (Shimadzu Corp., Kyoto, Japan) equipped with a diode array

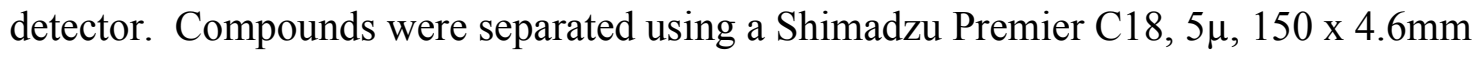
HPLC column and two buffers. Buffer A was 3\% phosphoric acid in water, and buffer B was HPLC-grade acetonitrile (Thermo Fisher Scientific, Inc., Waltham, MA).

Two start files (START-A and START-B) were written for use in equilibrating the HPLC system components (Tables 1,2). An analytical method was created for separation of compounds in the extracts (Table 3 ). The analysis period of the chromatograms was 90 minutes with a 30-minute re-equilibration period. 
Table 1. Parameters for START-A file. Flow rate $=0.8 \mathrm{~mL} / \mathrm{min}$

\begin{tabular}{cc}
\hline Time $(\min )$ & $\%{\text { Buffer } \mathrm{A}^{\mathrm{z}}}^{2}$ \\
\hline 0 & 5 \\
3 & 55 \\
18 & 95 \\
20 & Stop \\
21 & Ther
\end{tabular}

${ }^{\mathrm{z}}$ Buffer A was a 3\% phosphoric acid solution in water, and buffer B was HPLC-grade acetonitrile.

Table 2. Parameters for START-B file. Flow rate $=0.8 \mathrm{~mL} / \mathrm{min}$

\begin{tabular}{cc}
\hline Time (min) & $\%$ Buffer $\mathrm{A}^{\mathrm{z}}$ \\
\hline 0 & 95 \\
15 & 95 \\
16 & Stop \\
\hline
\end{tabular}

${ }^{\mathrm{z}}$ Buffer A was a 3\% phosphoric acid solution in water, and buffer B was HPLC-grade acetonitrile.

Table 3. Parameters for analytical method file. Flow rate $=0.6 \mathrm{~mL} / \mathrm{min}$

\begin{tabular}{cc}
\hline Time (min) & \% Buffer A \\
\hline 0 & 95 \\
5 & 95 \\
80 & 40 \\
90 & 10 \\
95 & 10 \\
105 & 95 \\
120 & 95 \\
121 & Stop \\
\hline
\end{tabular}

${ }^{\mathrm{z}}$ Buffer A was a 3\% phosphoric acid solution in water, and buffer B was HPLC-grade acetonitrile. 


\section{RESULTS}

\section{$\underline{\text { Aloe Mite Salivary Extract Processing and Hypocotyl Elongation Assay }}$}

The first objective of this investigation was to isolate a salivary extract from aloe mites to determine whether the sample contained compounds that altered plant growth and which might serve as a viable experimental treatment in the aloe biochemical defense response assay. The mites were submerged in oil and the aqueous phase of the salivary extract was obtained and used as a treatment in two hypocotyl elongation assays.

Statistical analysis was conducted using Minitab 16 statistical software (Minitab Inc., State College, PA). Analysis of Variance (ANOVA) tests were used to identify differences in mean hypocotyl lengths for the hypocotyl elongation assays, and to test the main and interaction effects of treatment and time. Tukey's HSD post hoc test $(\mathrm{p}<0.05)$ was used to identify the significantly different groups.

Normal probability plots and histograms of residuals in the first hypocotyl elongation assay indicated a moderate lack of normality or positive skewing, while residuals versus fitted values plots indicated a moderate lack of constant variance. A suitable transformation for the data was not identified; however, ANOVA is robust for data lacking normality (J. Sklar, personal communication, March 9, 2012) so the data from both hypocotyl elongation assays was used without transformation.

For the first hypocotyl elongation assay, the salivary extract increased hypocotyl elongation at $24 \mathrm{~h}$ (Fig. 1). The elongation that was observed in extract-treated hypocotyls was similar to the elongation produced by $10 \mu \mathrm{M}$ IAA (Table 4). 


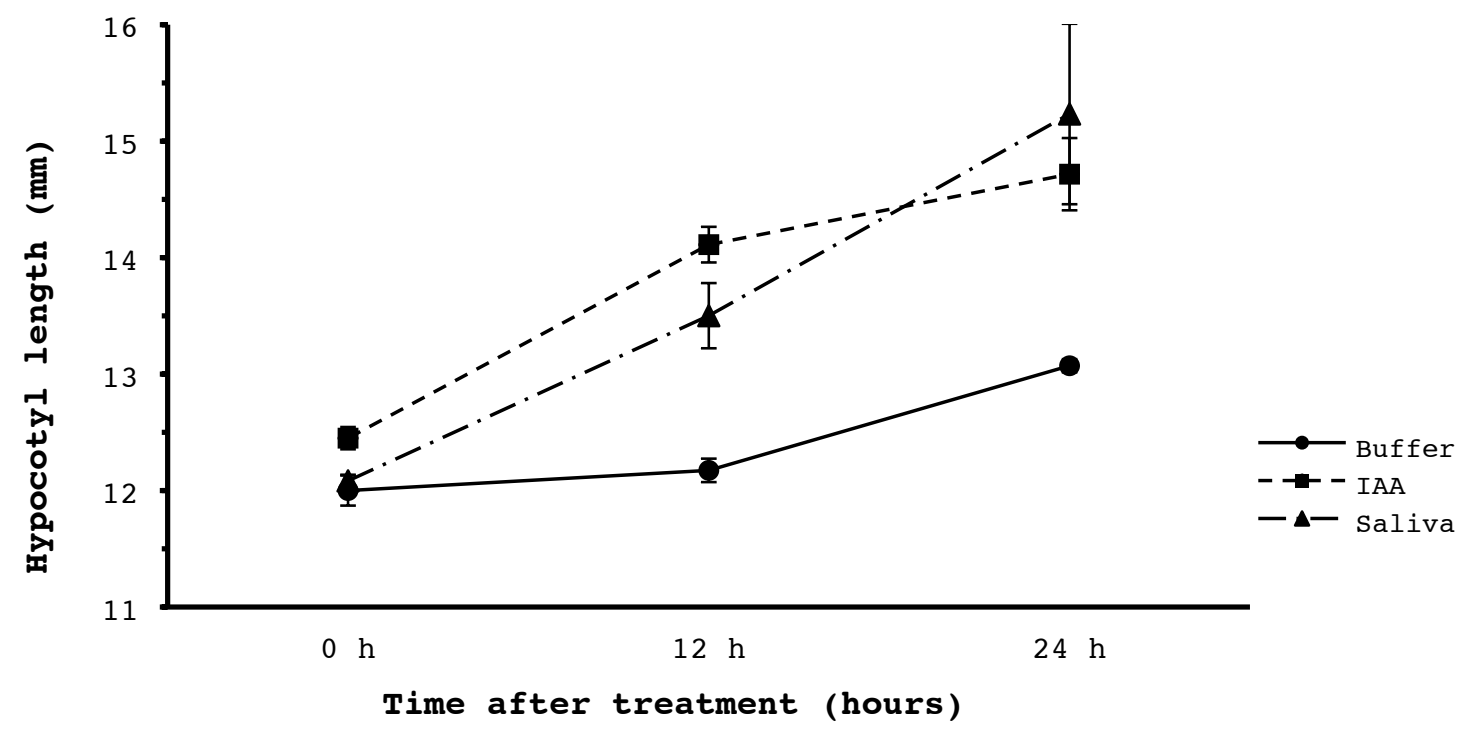

Fig. 1. The change in zucchini hypocotyl length in response to IAA, salivary extract, and buffer control over a $24 \mathrm{~h}$ period for replicate 1 . Error bars represent the standard error of the mean.

Table 4. Change in zucchini hypocotyl length over a $24 \mathrm{~h}$ period for replicate $1, \mathrm{n}=6$. Tukey grouping is at the $95 \%$ confidence interval level.

\begin{tabular}{|c|c|c|c|c|}
\hline Time $(\mathrm{h})$ & Treatment & Mean length (mm) & SEM & Tukey Grouping \\
\hline 0 & $\begin{array}{l}\text { Buffer } \\
\text { IAA } \\
\text { Saliva }\end{array}$ & $\begin{array}{l}12.000 \\
12.450 \\
12.083\end{array}$ & $\begin{array}{l}0.129 \\
0.0957 \\
0.0527\end{array}$ & $\begin{array}{r}\mathrm{E} \\
\mathrm{DE} \\
\mathrm{E}\end{array}$ \\
\hline 12 & $\begin{array}{l}\text { Buffer } \\
\text { IAA } \\
\text { Saliva }\end{array}$ & $\begin{array}{l}12.173 \\
14.112 \\
13.502\end{array}$ & $\begin{array}{l}0.101 \\
0.153 \\
0.280\end{array}$ & $\begin{array}{l}\mathrm{ABC}^{\mathrm{DE}} \\
\mathrm{BCD}\end{array}$ \\
\hline 24 & $\begin{array}{l}\text { Buffer } \\
\text { IAA } \\
\text { Saliva }\end{array}$ & $\begin{array}{l}13.072 \\
14.717 \\
15.233\end{array}$ & $\begin{array}{l}0.0566 \\
0.310 \\
0.775\end{array}$ & $\begin{array}{l}\mathrm{CDE} \\
\mathrm{AB}\end{array}$ \\
\hline
\end{tabular}


At $0 \mathrm{~h}$ there was a slight, unexpected difference in the length of IAA-treated hypocotyls compared with those of the salivary extract and buffer control; however, the difference was not significant (Table 4). A short delay between treatment and the initial $(\mathrm{t}=0)$ photocopying of hypocotyls may account for this difference, as the segments in IAA may have elongated slightly before photos were taken. At $12 \mathrm{~h}$, the elongation of hypocotyls observed for the IAA treatement was significantly greater than that of the buffer control. Furthermore, the increases in length of the hypocotyl segments treated with IAA was similar to that observed for other zucchini hypocotyls (Depta and Rubery, 1984; Wakabayashi et al., 1991), suggesting that the assay was carried out correctly. The saliva-treated hypocotyls at $12 \mathrm{~h}$ tended to be longer than those treated with buffer. At 24h, elongation of the IAA- and saliva-treated hypocotyls was significantly greater than those treated with buffer.

The salivary extract was tested again after 3 months of storage at $-80^{\circ} \mathrm{C}$, after all replications of the aloe biochemical defense response experiments were carried out. This second assay indicated, overall, only a slight, non-significant increase in the elongation of hypocotyls treated with salivary extract $(\mathrm{p}=0.6689$; Table 5). The mean length of IAAtreated hypocotyls was essentially the same as in the first assay (Fig. 1,2).

After 3 months storage of the salivary extract, there was no significant difference in the initial hypocotyl length for any of the treatments (Table 5). After 12h, hypocotyl elongation was significantly greater for the IAA treatment, but not the salivary extract treatment. At 24h, the IAA-treated hypocotyls were again significantly longer than those of controls and the salivary extract treatment, while there was no difference in elongation between saliva-treated and control hypocotyls. 


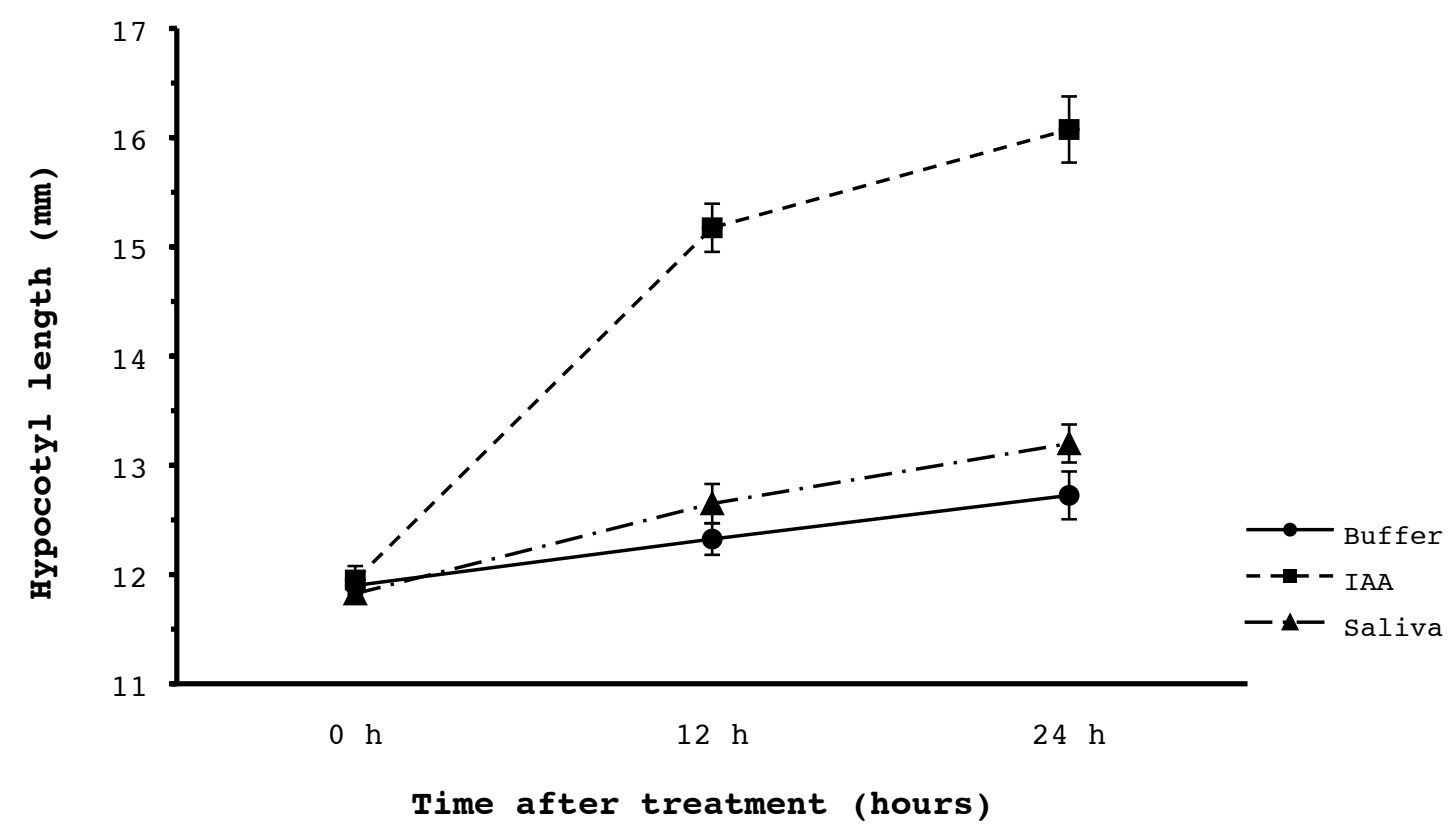

Fig. 2. The change in zucchini hypocotyl length in response to IAA, salivary extract, and buffer control over a $24 \mathrm{~h}$ period for replicate 2. Error bars represent the standard error of the mean.

Table 5. Change in zucchini hypocotyl length over a $24 \mathrm{~h}$ period for replicate $2, \mathrm{n}=10$. Tukey grouping is at the $95 \%$ confidence interval level.

\begin{tabular}{|c|c|c|c|c|}
\hline Time $(\mathrm{h})$ & Treatment & Mean length (mm) & SEM & Tukey Grouping \\
\hline \multirow[t]{3}{*}{0} & Buffer & 11.900 & 0.129 & $\mathrm{DE}$ \\
\hline & IAA & 11.950 & 0.128 & $\mathrm{DE}$ \\
\hline & Saliva & 11.825 & 0.0750 & $\mathrm{E}$ \\
\hline \multirow[t]{3}{*}{12} & Buffer & 12.325 & 0.101 & \multirow{3}{*}{${ }^{\mathrm{B}} \mathrm{CDE}$} \\
\hline & IAA & 15.175 & 0.221 & \\
\hline & Saliva & 12.650 & 0.180 & \\
\hline \multirow[t]{3}{*}{24} & Buffer & 12.725 & 0.0566 & \multirow[t]{3}{*}{$\mathrm{CD}$} \\
\hline & IAA & 14.717 & 0.310 & \\
\hline & Saliva & 13.200 & 0.174 & \\
\hline
\end{tabular}




\section{Aloe striata Biochemical Defense Response Assay}

The objective of this experiment was to observe the biochemical responses of Aloe striata Haworth plants treated with known and putative, plant defense elicitor molecules. To this end, A. striata plants were treated with JA, SA, mite salivary extract, and water. High performance liquid chromatography was performed on extracts prepared from plants harvested at 4,12 , and $24 \mathrm{~h}$, after which chromatograms were evaluated for unique peaks.

Analysis of HPLC Data Files

For each replication of the aloe biochemical defense response assay ("technical replicate"), all of the extracted, filtered plant samples were subjected to HPLC analysis and a unique chromatogram for each sample was produced and analyzed using Shimadzu CLASS-VP ver. 7.4 chromatography data acquisition and instrument control software (Shimadzu America, Columbia, MD). The term "biological replicate" (BR) was designated for each set of five plant samples per treatment combination, and the spectrum max plots within the BR were visually compared for similarities in retention time (RT) and absorbance. If the max plots of a given BR shared a very similar graphical pattern of RTs and absorption quantities with those of the corresponding control replicate (CR), then both the BR and CR were deemed to have virtually identical chemical compositions (Fig. 3). 


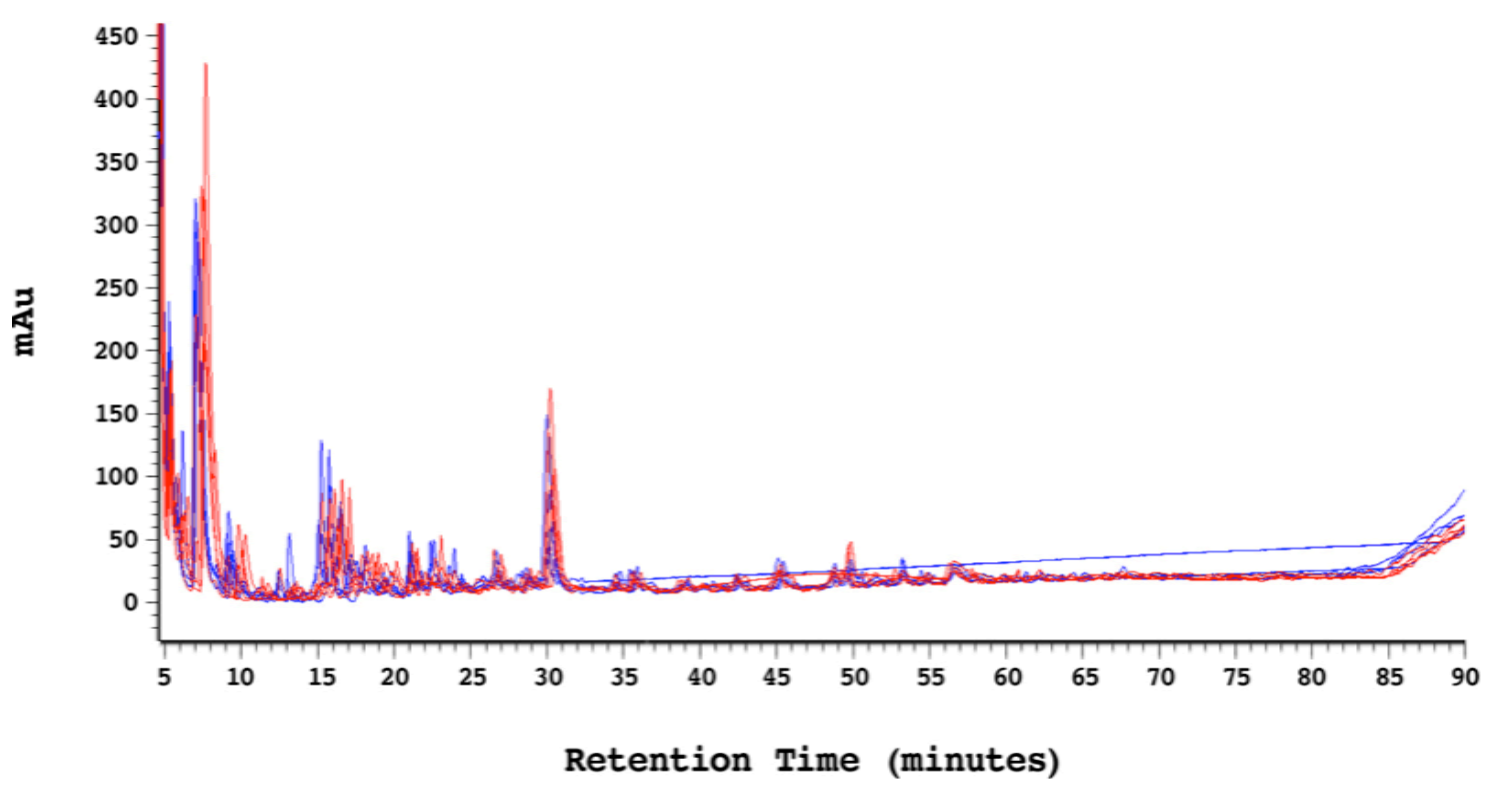

Fig. 3. An example of a spectrum max plot comparison between one biological replicate (BR; five red lines) and its corresponding control replicate (CR; five blue lines). The figure shows no unique peaks in either the BR or the CR.

If the collective chromatograms of a given BR exhibited or lacked specific peaks at particular RTs when compared with those of its corresponding CR, then that BR was deemed to possess (or lack) particular chemical compounds unique to that replicate. For each unique peak identified, the BR and CR chromatograms were opened in CLASS-VP and their spectrum maximum plot traces were visually aligned according to the overall graphical similarity of peak occurrence, relative RTs, and absorption values (Fig. 4). 


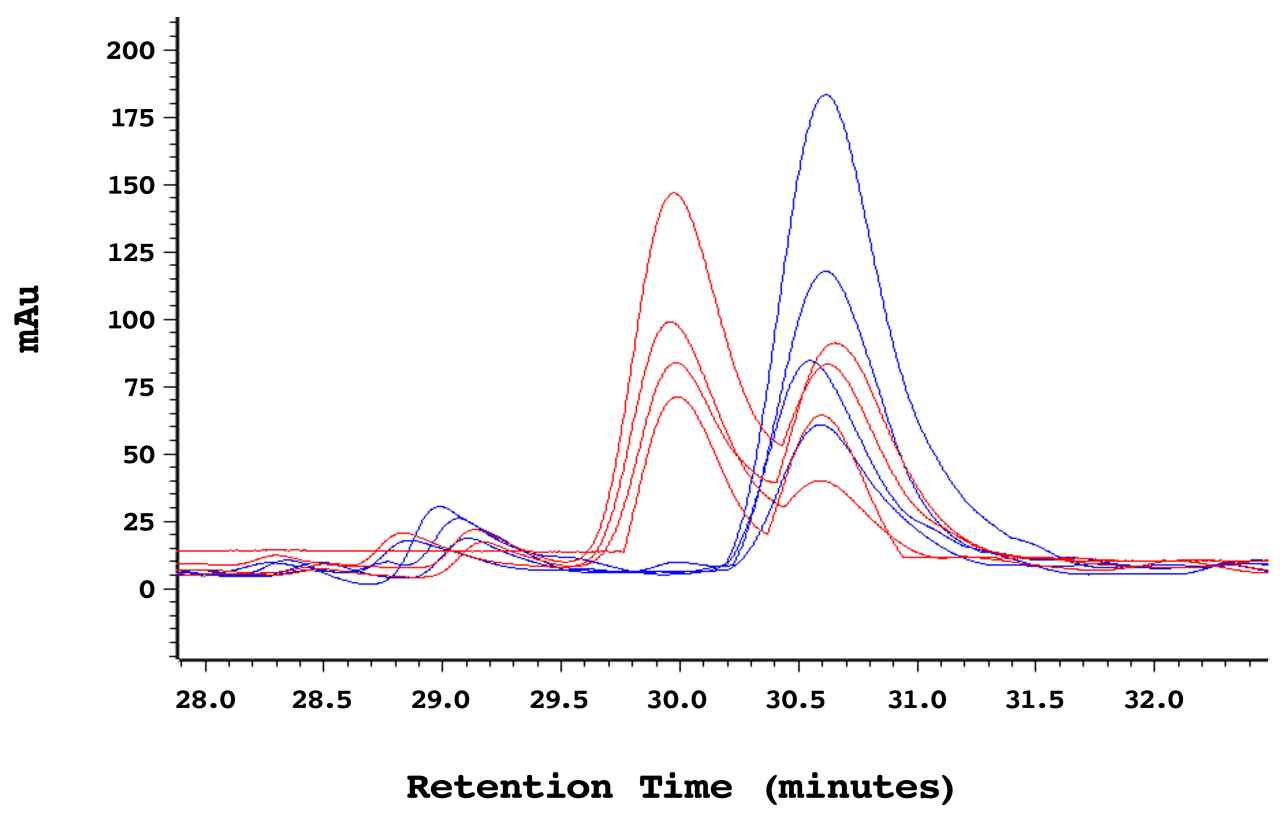

Fig. 4. An example of the spectrum max plot comparison of one unique peak between a biological replicate (BR) (red lines) and its corresponding control replicate (CR) (blue lines). A second peak that is not present in the $\mathrm{CR}$ can be seen in the chromatograms of the BR at an RT of approximately 30 minutes.

To verify the likelihood that aligned unique peaks represented the same chemical compound in each BR-CR comparison, the $\lambda$-maxima, RTs, and peak areas (PAs) for several adjacent peaks on either side of the given unique peak in each chromatogram were obtained from the spectrum max plot data and assessed for similarity. Once the ten collective chromatograms of a BR-CR comparison were assessed, the mean PA, standard deviation, and standard error of the mean were calculated for the peak in both the BR and CR.

\section{$\underline{\text { Statistical Analysis of Aloe Biochemical Defense Response Assays }}$}

As with the hypocotyl elongation assays, ANOVAs were calculated for aloe biochemical defense response assay data to compare the mean PAs of biological and 
control replicates across all combined technical replicates, and to detect significant differences in the main effects and interaction effects between treatment and time for unique peaks of interest. Tukey's HSD post hoc test $(\mathrm{p}<0.05)$ was again used to identify the significantly different groups.

Normal probability plots and histograms of residuals indicated a moderate lack of normality and either positive or negative skewing, while residuals versus fitted values plots indicated a moderate lack of constant variance, so a $\log _{10}$ transformation was applied to each PA data set for the aloe biochemical defense response assays. The resulting normal probability plots and histograms of residuals largely corrected normality problems and significantly reduced skewing, while residuals versus fitted values plots demonstrated largely constant variance.

After the statistical analysis, four unique peaks were found, each of which was present in either treated or control plants. These peaks represented a compound found in the water extract at 30 minutes (Peak A), the methanol extract at 30 minutes (Peak B), the methanol extract at 55 minutes (Peak C) and the methanol extract at 79 minutes (Peak D).

\section{Peak A Analysis}

Peak A was observed in water-extracted plant tissue, with an RT of approximately 30 minutes and a $\lambda$-max of $303 \mathrm{~nm}$. The compound represented by Peak A was significantly higher in plants sprayed with SA than in the control, JA- or extract-treated plants (Fig. 5). The compound in plants treated with JA occurred at a lower level than in the control plants, while the amount of the compound in the saliva-treated plants was 


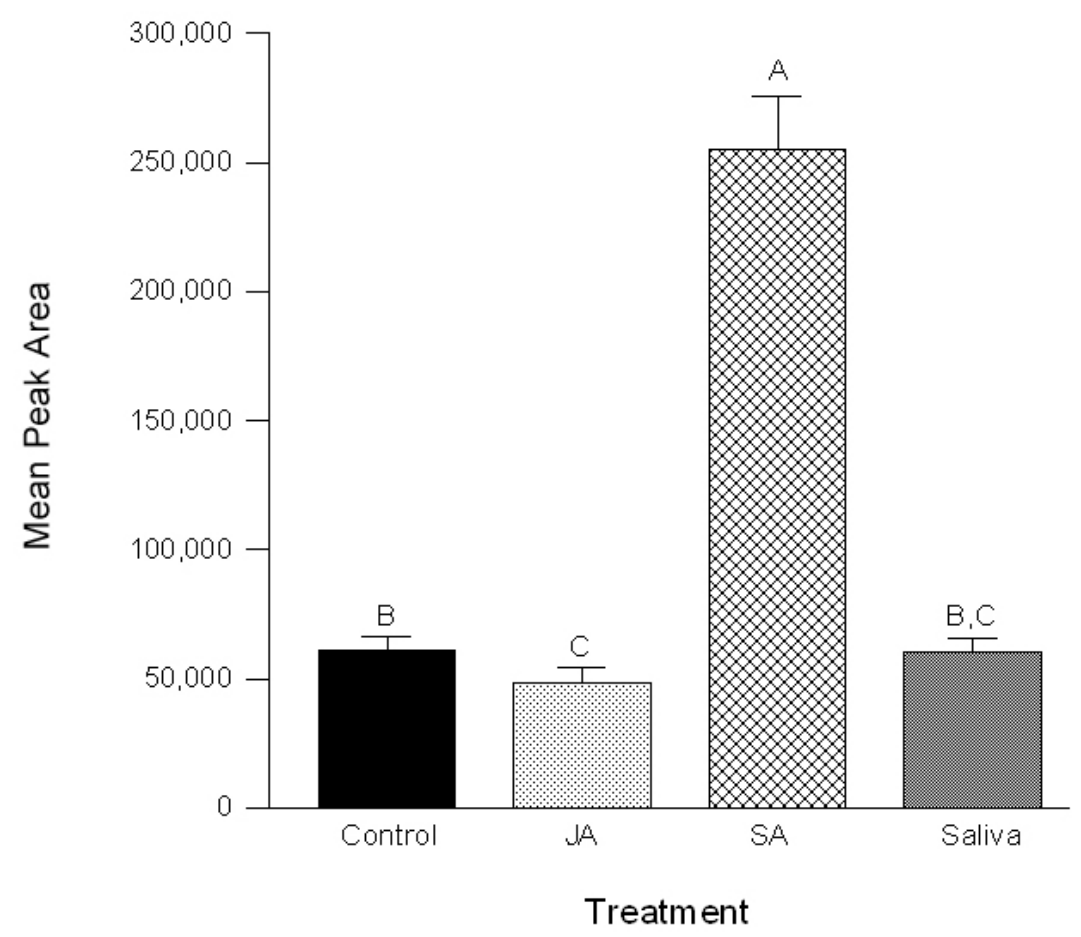

Fig. 5. Mean PAs of treated plants and controls for Peak A. The data from the untransformed data are shown, while the Tukey grouping is from the log-transformed data. Error bars represent the standard error of the mean.

intermediate between the levels found in the JA-treated and control plants. There were no significant differences between replicates $(\mathrm{p}=0.166)$ or time intervals $(\mathrm{p}=0.775)$.

The higher level of the compound represented by peak A in the SA-treated plants, combined with the $\lambda$-max of $303 \mathrm{~nm}$ for this peak (which corresponds to the $\lambda$-max of authentic SA), suggested that Peak A might be SA. Therefore, SA standards were prepared to test this possibility. The HPLC data from serial dilutions of an SA solution produced a single peak at approximately 30 minutes and yielded $\lambda$-max values of $302 \mathrm{~nm}$, $236 \mathrm{~nm}$, and $204 \mathrm{~nm}$, which were consistent with the $\lambda$-max values for SA-treated plants at $\mathrm{RT} \approx 30$ minutes. In order to quantitate the $\mathrm{SA}$ in the aloe samples, a standard curve for SA was created (Fig. 6). 


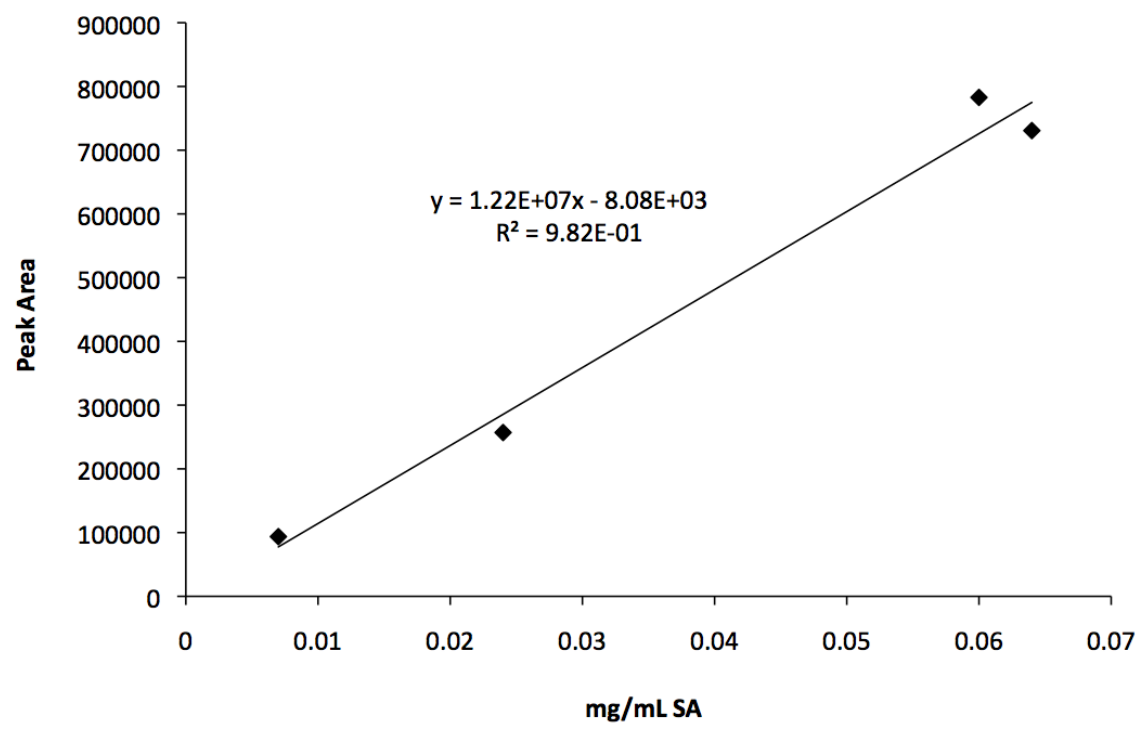

Fig. 6. Standard curve for salicylic acid produced using HPLC.

Using the standard curve, the SA concentration in the control plants (endogenous SA) was to be $0.004 \mathrm{mg} / \mathrm{ml}$, while the concentration in the SA-treated plants was 0.02 $\mathrm{mg} / \mathrm{ml}$. This represented a five-fold difference in SA concentration between the controland the SA-treated plants.

Peak B Analysis

Peak B was observed in methanol-extracted plant tissue, at an RT of approximately 30 minutes and with a $\lambda$-max of $303 \mathrm{~nm}$. An analysis of variance indicated that $\log _{10^{-}}$ transformed mean PAs were significantly different between treatments $(\mathrm{p}<0.001)$ and between replicates $(\mathrm{p}<0.001)$. 
The compound represented by Peak B was at a higher level in SA-treated plants than either in the JA-treated plants or controls, regardless of sampling time (Fig. 7). The level of compound in extract-treated plants overlapped the level found in the SA-treated plants $(p=0.4148)$ and controls $(p=0.9879)$ at $4 \mathrm{~h}$, while it matched that of the control plants at $12 \mathrm{~h}(\mathrm{p}=0.4585)$ and at $24 \mathrm{~h}(\mathrm{p}=0.5518)$.

Since the methanol-extracted plants that were sprayed with SA contained significantly more of the compound represented by Peak B, and since Peak B - like Peak A - also had a $\lambda$-max of $303 \mathrm{~nm}$, the SA concentration was calculated for plants subjected to this treatment. From the standard curve (Fig. 6), the calculated endogenous SA concentration in the control plants was essentially zero, while in the SA-treated plants it was $0.003 \mathrm{mg} / \mathrm{ml}$.

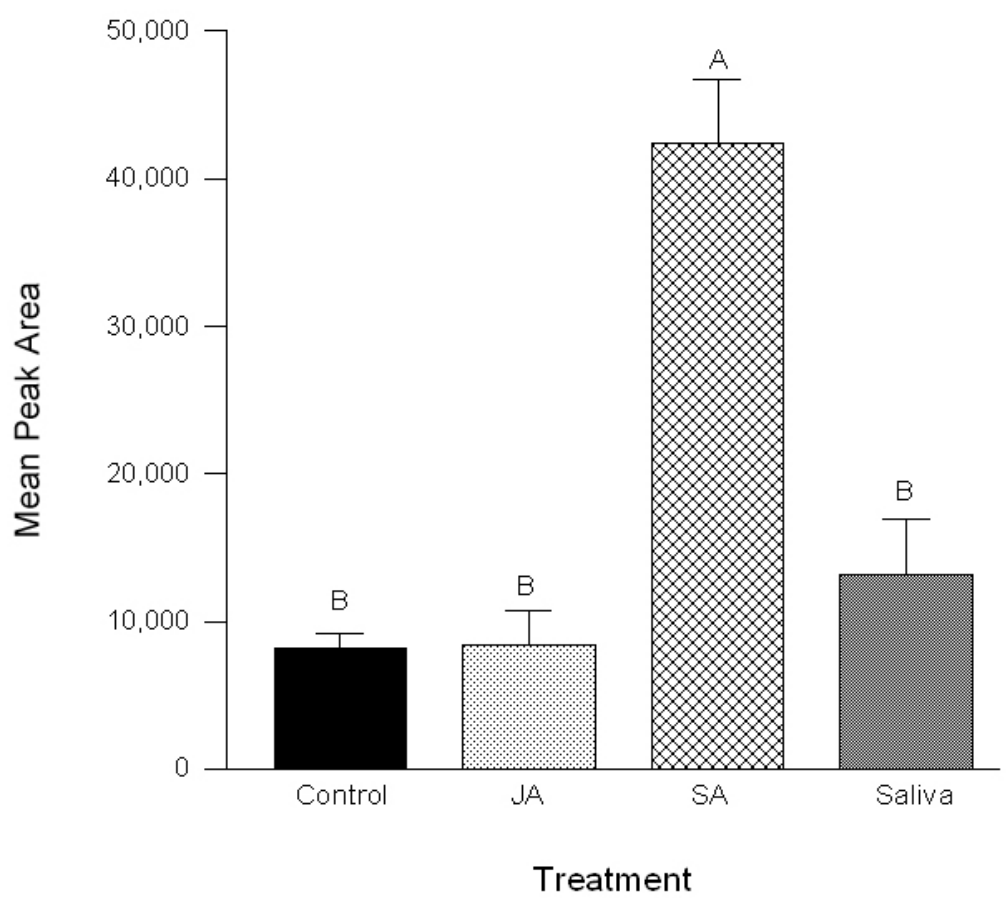

Fig. 7. Mean PAs of treated plants and controls for Peak B without respect to time. The data from the untransformed data are shown, while the Tukey grouping is from the log-transformed data. Error bars represent the standard error of the mean. 


\section{Peak C Analysis}

Peak C was observed in methanol-extracted plant tissue, and had an RT of approximately 55 minutes and a $\lambda$-max of $348 \mathrm{~nm}$. An analysis of variance indicated that the $\log _{10}$-transformed PA data was significantly different between treatments $(\mathrm{p}<0.001)$ and also between replicates $(\mathrm{p}=0.018)$. In the SA-treated plants, the amount of compound represented by Peak $\mathrm{C}$ was lower than that found in the control plants, while levels found in the JA and saliva-treated plants overlapped those of the controls and SA-treated plants (Fig. 8).

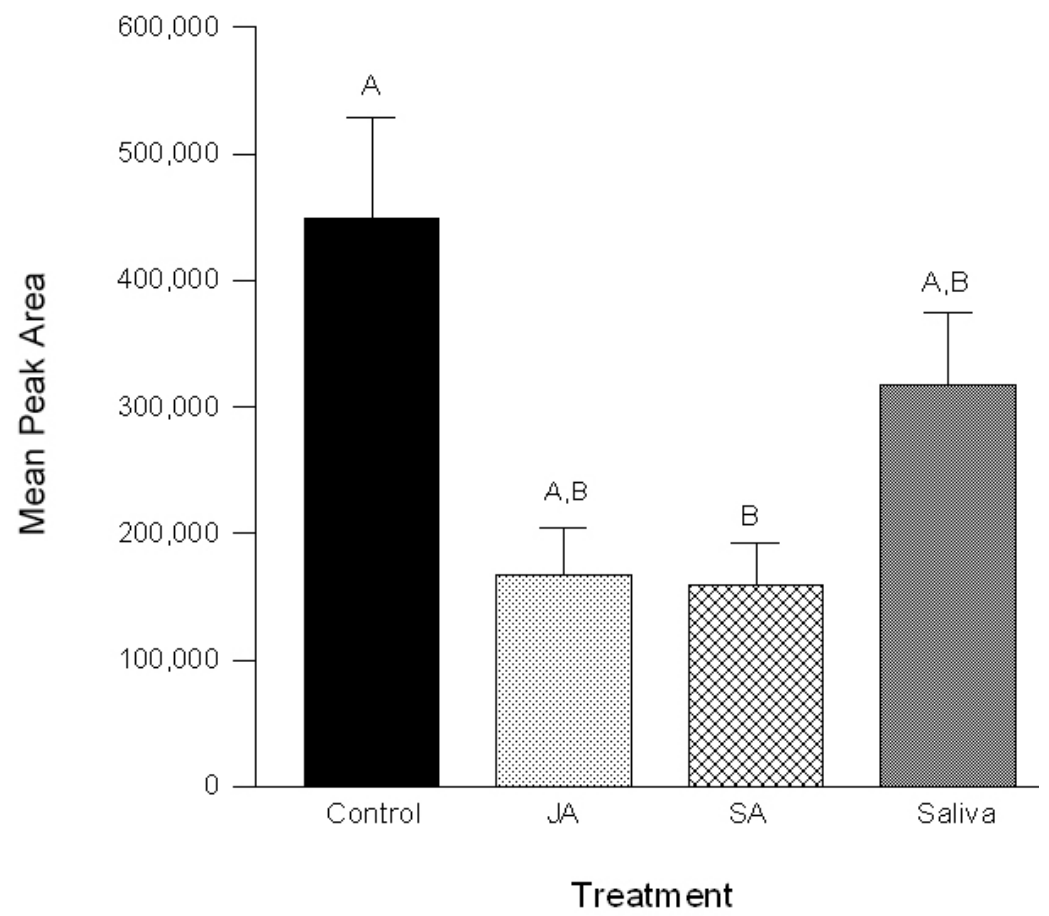

Fig. 8. Mean PAs of treated plants and controls for Peak C. The data from the untransformed data are shown, while the Tukey grouping is from the log-transformed data. Error bars represent the standard error of the mean. 


\section{$\underline{\text { Peak D Analysis }}$}

Peak D was observed in methanol-extracted plant tissue, and had an RT of approximately 78 minutes and a $\lambda$-max of $360 \mathrm{~nm}$. An analysis of variance of the Peak D data indicated that the $\log _{10}$-transformed mean PAs were significantly different between treatments $(\mathrm{p}<0.001)$ as well as replicates $(\mathrm{p}=0.007)$.

Levels of the compound represented by Peak D, in JA- and SA-treated plants, were significantly lower than the level found in control plants $(\mathrm{p}=0.0384$ and $\mathrm{p}=0.0313$, respectively), while the level in saliva-treated plants was intermediate to the levels found in the other two treatments and control (Fig 9).

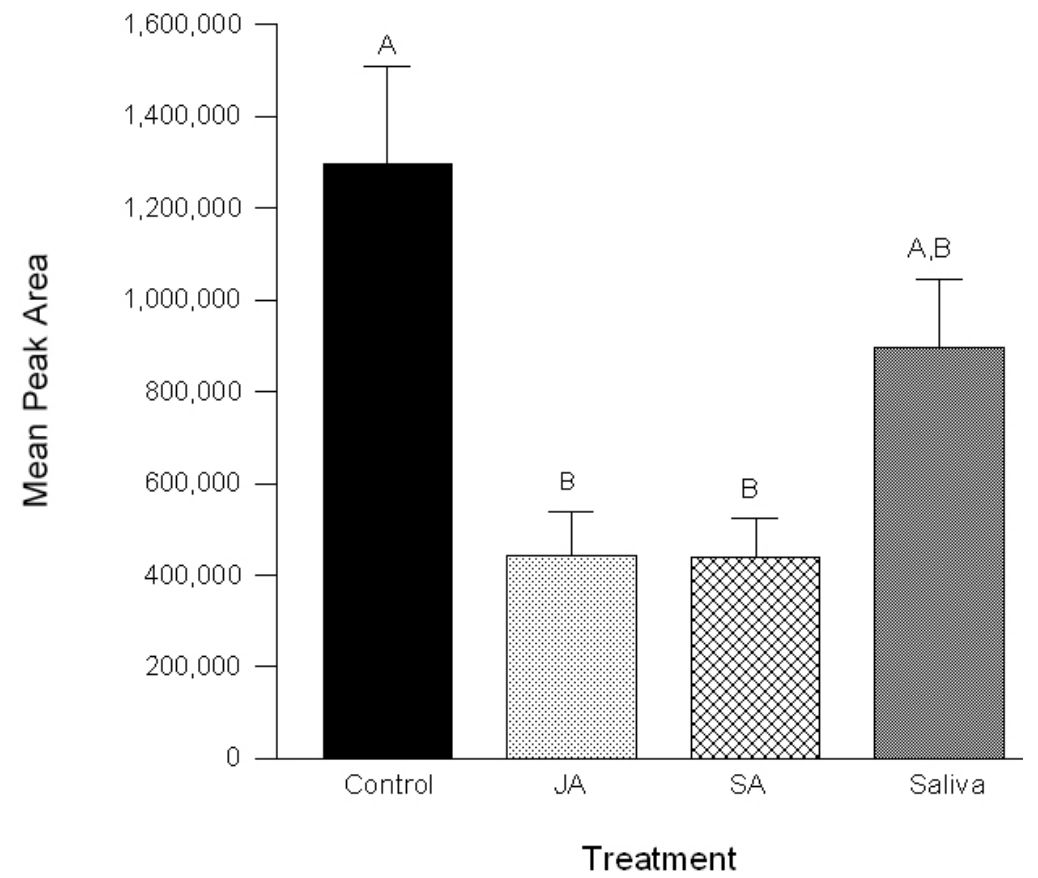

Fig. 9. Mean PAs of treated plants and controls for Peak D. The data from the untransformed data are shown, while the Tukey grouping is from the log-transformed data. Error bars represent the standard error of the mean. 


\section{DISCUSSION}

Plant defense in the genus Aloe has not been studied extensively. In an effort to determine whether the chemical constituents in aloe plants change during perceived

attack, an experiment was designed to treat young Aloe striata plants with several plant defense compounds: SA, JA, and the salivary extract from aloe mites. The salivary extract from aloe mites was chosen because of the possible existence of plant defense elicitor compounds in eriophyid mite saliva (de Lillo and Monfreda, 2004).

\section{Hypocotyl Elongation Assays}

In the first hypocotyl elongation assay, IAA-treated hypocotyls exhibited a wellknown pattern of cellular elongation: a highly increased rate of elongation from 0 to $12 \mathrm{~h}$ was followed by a reduced (though still positive) rate of elongation from 12 to $24 \mathrm{~h}$ (Qin et al., 2005; Gray et al., 1998; Moore, 1967). Saliva-treated hypocotyls elongated in a pattern similar to that of the IAA-treated segments; however, the saliva-treated hypocotyls were longer than the controls after $24 \mathrm{~h}$, only. At all time intervals, the lengths of hypocotyl segments treated with IAA and salivary extract were the same (Table 4).

Interestingly, from 12 to $24 \mathrm{~h}$, the rate of elongation of the saliva-treated hypocotyls appeared constant, whereas that of the IAA-treated hypocotyls declined. It is possible that hypocotyl elongation induced by mite salivary extract might continue for a longer period of time than measured in these assays, suggesting that the putative elicitor in the mite salivary extract does not function like a typical plant hormone: its action appears to follow a different time course than that of small molecules such as IAA, other auxins, 
cytokinins, and abscissic acid (Moore, 1967; Gray et al., 1998). With a slower initiation period and a longer bioactivity rate than IAA and other plant growth promoting hormones, the salivary extract might include an elicitor that functions as a herbivoreassociated molecular pattern (HAMP), with a different mode of action and a less direct effect on cell membrane architecture. This might require more time to generate a series of downstream secondary defense responses than typical plant hormones.

A second hypocotyl elongation assay was carried out after the salivary extract showed a dramatic decrease in bioactivity. In this series of assays, the extract-induced elongation was not different from that of the control hypocotyls at 12 and $24 \mathrm{~h}$. There was a slight increase in elongation at $24 \mathrm{~h}$, which was not significant. This assay was performed correctly as the IAA-treated hypocotyls had virtually the same elongation as was found in the first assay. The decrease in bioactivity may have been caused by a freezer malfunction which caused the storage temperature of the salivary extract to increase to room temperature. The saliva sample also underwent numerous freeze-thaw cycles during the course of the aloe biochemical defense response experiments, and this may have also contributed to the loss of bioactivity.

The first elongation assay indicated that a bioactive salivary extract capable of producing hypocotyl elongation was isolated, so it seems reasonable to believe that if the extract had a hyperplastic effect on zucchini hypocotyls, the compounds it contained might also be involved in the proliferative growth observed in aloe cancer. It also seems likely that these compounds would elicit a defense response from aloes. 


\section{Detection of Aloe Compounds that May be Altered During Plant Defense}

The primary objectives of this paper were 1) to investigate the bioactivity of a putative specific HAMP (aloe mite salivary extract) and the classical defense compounds JA and SA, and 2) to find compounds in aloe plant tissues with concentrations that changed during the aloe defense response. The chromatograms of treated plants were compared with control chromatograms. Peaks with highly similar retention times (RT) and $\lambda$-max were presumed to be the same compound. Four peaks of interest were identified and subjected to statistical analysis.

\section{Aloe Mite Salivary Extract}

The effects of mite salivary extract on aloe plant metabolism appeared to be weak in the aloe biochemical defense response assays. For the unique compounds represented by Peaks A (Fig 5), C (Fig 8) and D (Fig 9), PAs were different between JA-treated and control plants, while the PAs for Peaks A, C, and D of the saliva-treated plants were intermediate between those of JA-treated plants and the controls. An approximate 1.5fold reduction in the levels of compounds represented by Peaks C and D, compared with the controls, was observed in the saliva-treated plants. This suggests that a compound present in the control plants underwent a biochemical transformation in the saliva-treated plants, as part of a plant defense response. This is analogous to the defense response observed in the family Brassicaceae. Physical damage by herbivory causes myrosinases to contact and hydrolyze glucosinolates to isothiocyanate intermediates, creating more toxic and herbivore-specific defense compounds while decreasing the levels of glucosinolate parent compounds (Winde and Wittstock, 2011). 
For the compound represented by Peak B, the PA from the JA-treated plants was the same as that of the controls, and the PA of Peak B from the saliva-treated plants was the same as the control and JA-treatments, except at 4h (Fig. 7). This observation was puzzling, considering that Peaks A and B likely represented SA in the water- and methanol extracts, respectively, and the relative PAs of Peaks A and B from each treatment should have remained the same. However, the qualitative differences between Peak A and Peak B may be due to the sequential extraction of these samples first by water and then by methanol.

The salivary extract had little effect on the levels of the 4 compounds of interest, which may have resulted from an inadequate concentration of the putative elicitor compound. The identity of a specific eriophyid mite salivary extract compound that might modulate plant defense responses is unknown, and the determination of such a compound was not attempted. It is probable that the putative elicitor was initially present, however, considering the first hypocotyl assay in which there was a greater hypocotyl length and elongation rate for extract-treated plants than for the controls.

Compounds that produce hypocotyl elongation may not induce plant defense responses. The constant high rate of elongation in saliva-treated hypocotyls over 24h, compared to the decreasing rate in IAA-treated segments, suggests that a 24-hour time course in the aloe experiments may have been insufficient for measuring the putative mite-saliva elicitor's bioactivity.

Low extract bioactivity may have resulted from the substantial increase in storage temperature, due to a freezer malfunction, that the sample sustained for two weeks. This occurred between the first and second hypocotyl elongation assays and is the likely cause 
of the dissimilar elongation results between the two experiments. The aloe experiments were also conducted after the freezer malfunction. As it was necessary to thaw and refreeze the salivary extract several times, these freeze-thaw cycles may have contributed to a degradation of the putative elicitor compound.

The application method for the salivary extract possibly contributed to its lack of extract effect in saliva-treated aloes. While the SA-, JA-, and control treatments were sprayed onto plants as a mist, the extract-treated plants received 4-5 gentle perforations with a tuberculin needle that was first dipped into the salivary extract. It is possible that the elicitor compound did not adsorb to the needle during perforation at volumes adequate to initiate biochemical changes within the plants.

Aloe mite stylet lengths are very small, with the stylets penetrating less than $5 \mu$ into the plant epidermis (Nault, 1997). The needle-piercing technique used for transmission of the salivary extract likely penetrated several millimeters beyond the epidermal tissues and probably produced extensive tissue damage, activating a wounding response. Wounding plant tissues typically results in wound-induced resistance (WIR) (Howe and Jander, 2008; Kim et al., 2012), producing damage-associated molecular patterns (DAMPs) (Boller and Felix, 2009; Erb et al., 2012). A wounding response in salivatreated plants may have occurred; however, it was not observed in the HPLC chromatograms.

The change in aloe leaf water potential during perforation could also have had an effect on the uptake of the salivary extract. Pricking the leaves could have caused a considerable outward force of aloe leaf internal water pressure which might have prevented the diffusion of saliva elicitor into the plant in sufficient amounts to trigger a 
plant-defense response effect.

\section{$\underline{\text { Salicylic Acid Treatment - Peak A and B are Probably SA }}$}

The unique peak at $\mathrm{RT} \approx 30$ minutes that was present in both water- and methanolextracted samples (Peak A and Peak B, respectively) probably represents salicylic acid. SA was expected to appear in SA-treated plant extracts because it was applied to the plants in spray form. In fact, the peak areas (Peak A and B) at RT $\approx 30$ in SA-treated plants was higher than in control plants by a factor of 4- to 5-fold. This can be compared to a 0 - to 1-fold difference at the same RT between all controls, JA-, and salivary extracttreated plants, in both water- and methanol-extracted samples.

An authentic SA standard was prepared and it had the same RT and absorption characteristics as Peaks A and B, which makes it likely that these peaks represented SA. Ortho-salicylic acid (SA) does not appear to have been found in aloes though this study suggests that SA is present in Aloe striata. Para-salicylic acid has been quantitated in $A$. ferox (Loots, 2007); however, this compound is not the isomer involved in plant defense, and derives from early steps in the shikimate biosynthesis pathway. Ortho-salicylic acid is synthesized by an entirely different pathway that uses benzoic acid as the initial precursor (Dewick, 1997).

The amount of SA present in aloe samples was quantitated by creating a standard curve. After water extraction, the concentration of SA in control plants was found to be approximately $4 \mu \mathrm{g} / \mathrm{mL}$ and represented only endogenous SA. In SA-treated plants, the total concentration was approximately $20 \mu \mathrm{g} / \mathrm{mL}$. It is likely that this nearly five-fold increase in SA concentration between water-extracted control and SA-treated plants is 
due to the residual exogenous SA from the treatment application. After methanol extraction, the SA concentration in SA-treated aloes $(3 \mu \mathrm{g} / \mathrm{mL})$ was well below the 20 $\mu \mathrm{g} / \mathrm{mL}$ observed in the water-extracted SA-treated plants, while in control plants the SA concentration was virtually zero. These observations strongly suggest that all of the endogenous SA in aloe plants was removed by the extraction processes.

It is likely that the $3 \mu \mathrm{g} / \mathrm{mL}$ in the methanol-extracted plants represents residual SA that was not removed during the single water extraction. SA dissolves poorly in water, with a solubility of $20 \mu \mathrm{g} / \mathrm{mL}$ at $298 \mathrm{~K}$ (Shalmashi and Ellassi, 2008). The concentration of SA represented by the SA-treated plants in Peak A was also $20 \mu \mathrm{g} / \mathrm{mL}$, suggesting that the maximum amount of SA was removed during water extraction. It appears likely that Peak B represents the remaining SA that was removed during methanol extraction, giving a total SA concentration of $23 \mu \mathrm{g} / \mathrm{mL}$ for the SA-treated plants (of which $4 \mu \mathrm{g} / \mathrm{mL}$ was endogenous SA).

A wide range of endogenous SA concentrations has been found in different plants, ranging from $0.01 \mu \mathrm{g} / \mathrm{g}$ in tobacco (Malamy et al., 1990) to $30 \mu \mathrm{g} / \mathrm{g}$ in rice (Yang et al., 2004). The endogenous SA concentration of Aloe striata falls near the high end of this range. The compound(s) represented by Peak A was not isolated and further characterized, so it cannot be conclusively stated that this peak, in fact, represents SA. The preponderance of evidence, however, suggests that Peaks A and B represent SA.

It is reasonable to assume that SA would be present in aloe plants, as it is a very common plant defense compound (Arfan, 2007; Delaney, 2010; Hayat et al., 2007, Kadioglu et al., 2011). Elevated levels of SA could be expected to be found in the JAand salivary extract-treated plant samples, however, the SA concentrations in JA- and 
saliva-treated plants were significantly lower than that of the control plants. One explanation for this observation is that the SA pathway in all plants appears to be largely independent of the JA-mediated plant defense responses. Furthermore, DAMPs (which should have been produced by needle-wounding during saliva-extract application) also appear to act in the JA-mediated pathway (Ballaré, 2011; Erb et al., 2012). This may account for the fact that a small reduction was observed in the SA concentrations (Peak A) in JA-treated plants, while no change in SA concentration was observed in extracttreated plants.

\section{$\underline{\text { Responses of Aloes to JA Treatment }}$}

JA is well established as a primary signal in regulating plant defense responses to herbivory and physical damage (Pieterse et al., 2009; Schmelz et al., 2009), whereas SA is more closely associated with pathogen-related responses (Erb et al., 2012). For JAtreated plants, the PA's for Peaks C and D were significantly lower than those from control plants by a factor of about 3-fold, similar to that of salivary extract-treated plants. It appears that the compounds represented by Peaks $\mathrm{C}$ and $\mathrm{D}$ may have been converted into other compounds during defense responses.

It is interesting that extracts from the JA-treated plants did not contain any observable unique compounds that increased during JA treatment. Since there was a large decrease in the compounds represented by Peaks C and D, it seems logical that the metabolites of those peaks would be detectable. Those peaks, however, were not observed, possibly due to poor light absorption from the photodiode array, conversion into numerous metabolic intermediates (none of which exhibited a high enough 
concentration for detection), or an inability to elute from the C-18 reverse-phase HPLC column that was used for separations.

Although the reduction in PA's for Peaks C and D in JA-treated plants was significant, there are, nonetheless, several reasons why the JA response may not have been optimal. In this experiment, JA was dissolved in water and sprayed on aloe plants. Considering this application method, and given the compound's volatile nature, it is difficult to estimate the actual JA concentration achieved in this treatment. The initial JA application was $0.01 \%$, which is an optimal concentration for a defense response in Arabidopsis thaliana (van Poecke \& Dicke, 2002; Rubino, 2006), however, the optimal concentration that might elicit such a response from $A$. striata is unknown, and the concentration used in this experiment may not have been within range of that value.

Both excessive and insufficient concentrations of exogenous JA during experimental treatment have failed to produce a response in some plants (Hawkins et al., 2007; Nojiri et al., 1996). The actual concentration of volatile JA inside the light-resistant bags housing $A$. striata during experimental treatment was not measured, so a non-diffusible, excessive concentration of endogenous and exogenous JA may have accumulated in the enclosed environment. The bags may have also allowed ethylene to accumulate, which can affect plant metabolism (Acharya and Assmann, 2009).

A number of physical and spatio-temporal factors may have played a role in modulating the uptake of the JA and SA treatments by the aloe plants. A. striata plants open their stomata at night and close them during the day, like all Crassulacean metabolism (CAM) plants (Sheteawi, 2001). If circumstances were such that stomata were, in fact, closed during experimental treatment, then the uptake of the sprayed 
treatments (JA and SA) by the plants may have been reduced.

Factors that force stomatal closure in CAM plants include sub-optimal: air and leaf temperatures, relative humidities, and internal $\mathrm{CO}_{2}$ concentrations (Nobel, 1976; Jones, 1992; Rodriguez-Garcia et al., 2006). Neither these factors, nor the circadian response of A. striata plants to these factors, were monitored during or prior to treatment applications. Ten weeks before treatments were applied, the photoperiod was reversed temporally, in an attempt to force "night-time" stomatal opening to coincide with daytime hours for experimental treatment applications. The aloes' circadian rhythms likely adapted to this manipulation; however, considering that, from the time of treatment until sacrifice (up to $24 \mathrm{~h}$ in some cases), the plants remained enclosed in plastic bags and were moist from spray treatment. Therefore, some combination of physical factors may have combined to force stomatal closure during this period.

\section{Possible Identity of Peaks C and D}

The compounds represented by Peaks C and D must be more hydrophobic than Peaks A and B (presumably SA) because they eluted from the C-18 reverse phase HPLC column at later RTs, when the percentage of the more hydrophobic acetonitrile solvent was higher. Peaks C and D had lambda-maxima of $348 \mathrm{~nm}$ and $360 \mathrm{~nm}$, respectively, in the wavelength range where flavonoid compounds such as anthocyanins, flavones, flavonols, and isoflavones absorb light (Liang et al., 2011). It is possible that Peaks C and $\mathrm{D}$ represent flavonoid compounds as these are known to be involved in plant defense (Treutter, 2006).

In addition, the anthrone-C-glycosides barbaloin, nataloin, and homonataloin have 
been isolated from Aloe mutabilis, and also have lambda maxima in the same range as Peaks C and D (Chauser-Volfson and Gutterman, 1998). Analysis of the distribution of two other anthrone-C-glycosides, homonataloin and aloeresin, in the leaves of Aloe hereroensis found a pattern characteristic of plant defense compounds, where concentrations were highest in young leaves, the adaxial region of leaf centers, and the abaxial portion of entire leaves. The researchers speculated that this distribution pattern may constitute an anti-herbivory defense strategy by the aloe species (Chauser-Volfson et al., 2002).

Further investigation of the compounds represented by Peaks C and D should be conducted in an effort to identify and characterize their potential roles in aloe plant defense metabolism. 


\section{CONCLUSIONS}

Four peaks were identified as being statistically different in saliva-, JA-, and SAtreated plants. Peaks A and B exhibited retention times and spectral characteristics that matched authentic salicylic acid and were, therefore, likely to represent endogenous and exogenous SA in Aloe striata plants. This appeared to be the first time that orthosalicylic acid had been observed in an aloe species. Two other compounds (Peaks $\mathrm{C}$ and D) varied between experimental treatments and were likely to be compounds that are converted to active plant defense metabolites. These compounds should be further characterized. 


\section{LITERATURE CITED}

Agrawal, A.A. (2011). Current trends in the evolutionary ecology of plant defense. Funct. Ecol. 25, 421-433.

Agrios, G.N. Plant Pathology. 2004. Plant pathology (5th). Academic Press, New York, NY.

Ballaré, C.L. 2011. Jasmonate-induced defenses: a tale of intelligence, collaborators and rascals. Trends Plant Sci. 16, 249-257.

Bethke, J.A. 2010. Integrated pest management of the aloe mite. Regional Report San Diego and Riverside Counties 14, 1. Retrieved from

http://ucanr.org/sites/UCNFAnews/Regional_Report_San_Diego_and_Riverside_Co unties/Spring_2010_Integrated_pest_management_of_the_aloe_mite/

Boller, T., and Felix, G. 2009. Microbe-associated molecular patterns and danger signals by pattern-recognition receptors. Annu. Rev. Plant Biol. 60, 379-406.

Boller, T., and He, S.Y. 2009. Innate immunity in plants: An arms race between pattern recognition receptors in plants and effectors in microbial pathogens. Science 324, 742-743.

Chauser-Volfson, E., and Gutterman, Y. 1998. Content and distribution of anthrone- $C$ glycosides in the South African arid plant species Aloe mutabilis growing in the direct sunlight and the shade in the Negev Desert of Israel. J. Arid Environ. 40, 441-451.

Chauser-Volfson, E., Shen, E., Hu, Z., and Gutterman, Y. 2002. Anatomical structure and distribution of secondary metabolites as a peripheral defense strategy in Aloe hereroensis leaves. Bot. J. Linn. Soc. 138, 107-116.

Constabel, C.P. 1999. A survey of herbivory-inducible defensive proteins and phytochemicals, p. 137-166. In: Agrawal, A.A., Tuzun, S., and Bent, E. (eds). Induced plant defenses against pathogens and herbivores: Biochemistry, ecology and agriculture. APS Press, St. Paul.

de Lillo, E., and Monfreda, R. 2004. Salivary secretions of eriophyoids (Acari: Eriophyoidea): first results of an experimental model. Exp. Appl. Acarol. 34, 291306.

de Wit, P.J.G.M. 2007. How plants recognize pathogens and defend themselves. Cell. Mol. Life Sci. 64, 2726-2732.

Deinhart, N. 2011. Tiny monsters: Aceria aloinis. Cact. Succ. J. 83, 120-122. 
Denmark, H.A., and Keifer, H.H. 1979. A mite, Eriophyes aloinis (Keifer) (Acarina: Eriophyidae). Fla. Dept. Agr. And Consum. Serv. Ent. Cir. 206, 2 pp.

Depta, H., and Rubery, P.H. 1984. A comparative study of carrier participation in the transport of 2,3,5-triiodobenzoic acid, indole-3-acetic acid, and 2,4dichlorophenoxyacetic acid by Cucurbita pepo L. hypocotyl segments. J. Plant Physiol. 115, 371-387.

Dewick, P.M. 1997. Medicinal natural products, a biosynthetic approach. John Wiley and Sons, Chichester, UK.

Erb, M., Meldau, S., and Howe, G.H. 2012. Role of phytohormones in_insect-specific plant reactions. Trends Plant Sci. 17, 250-259.

Farmer, E.E. 2007. Plant biology: Jasmonate perception machines. Nature 448, 659660.

Felton, G.W., Tumlinson, J.H. 2008. Plant-insect dialogs: Complex interactions at the plant-insect interface. Curr. Opin. Plant Biol. 11, 457-463.

Fowler, J.H., Narvaéz-Vasquéz J., Aromdee, D.N., Pautot, V., Holzer, F.M.,and Walling, L.L. 2009. Leucine aminopeptidase regulates defense and wound signaling in tomato downstream of jasmonic acid. Plant Cell 21, 1239-1251.

Franco, O. L. 2011. Peptide promiscuity: An evolutionary concept for plant defense. FEBS Lett. 585, 995-1000.

Glazebrook, J. 2005. Contrasting mechanisms of defense against biotrophic and necrotrophic pathogens. Annu. Rev. Phytopathol. 43, 205-227.

Gozzo, F. 2003. Systemic acquired resistance in crop protection: From nature to a chemical approach. J. Agric. Food Chem. 51, 4487-4503.

Grace, O.M., Simmonds, M.S.J., Smith, G.F., and van Wyk, A.E. 2009. Documented utility and biocultural value of Aloe L. (Asphodelaceae). Econ. Bot. 63, 167-178.

Gray, W.M., Östin, A., Sandberg, G., Romano, C.P., and Estelle, M. 1998. High temperature promotes auxin-mediated hypocotyl elongation in Arabidopsis. Proc. Natl. Acad. Sci. USA, 95, 7197-7202.

Griffin, K. January 13, 2006. 18539 Aliso Canyon Road, Rancho Santa Fe, CA 92091.

Halitschke, R., Schittko, U., Pohnert, G., Boland, W., Baldwin, I.T. 2001. Molecular interactions between the specialist herbivore Manduca sexta (Lepidoptera, Sphingidae) and its natural host Nicotiana attenuata. III. Fatty acid-amino acid 
conjugates in herbivore oral secretions are necessary and sufficient for herbivorespecific plant responses. Plant Physiol. 125, 711-717.

Hayat, S., Ali, B., and Ahmad, A. 2007. Salicylic acid: biosynthesis, metabolism and physiological role in plants, p. 1-14. In: S. Hayat and A. Ahmad (eds.). Salicylic Acid - A Plant Hormone. Springer, Dordrecht, Netherlands.

Heil, M. 2009. Damaged-self recognition in plant herbivore defense. Trends Plant Sci. $14,356-363$.

Howe, G.A., and Jander, G. 2008. Plant immunity to insect herbivores. Annu. Rev. Plant Biol. 59, 41-66.

Jones, H. 1992. Plants and microclimate: A quantitative approach to environment plant physiology, second ed., pp. 264-276. Great Britain: Cambridge University Press.

Jones, J.D., and Dangl, J.L. 2006. The plant immune system. Nature 444, 323-329.

Kawazu, K., Mochizuki, A., Sato, Y., Sugeno, W., Murata, M., Seo, S., and Mitsuhara, I. 2012. Different expression profiles of jasmonic acid and salicylic acid inducible genes in the tomato plant against herbivores with various feeding modes. Arthropod-Plant Inte. 6, 221-230.

Kim, J., Tooker, J.F., Luthe, D.S., De Moraes, C.M., Felton, G.W. 2012. Insect eggs can enhance wound response in plants: A study system of tomato Solanum lycopersicum L. and Helicoverpa zea Boddie. PLoS ONE 7(5): e37420.

Koornneef, A., Leon-Reyes, A., Ritsema, T., Verhage, A., Den Otter, F.C., Van Loon, L.C., Pieterse, C.M.J. 2008. Kinetics of salicylate-mediated suppression of jasmonate signaling reveal a role for redox modulation. Plant Physiol. 147, 13581368 .

Leon-Reyes A., Spoel, S.H., De Lange, E.S., Abe, H., Kobayashi, M., Tsuda, S., Millenaar, F.F., Welschen, R.A., Ritsema, T., and Pieterse, C.M. 2009. Ethylene modulates the role of NONEXPRESSOR OF PATHOGENESIS-RELATED GENES1 in cross talk between salicylate and jasmonate signaling. Plant Physiol. 49, 1797-809.

Loots, Du T., Van der Westhuizen, F. H., and Botes, L. 2007. Aloe ferox leaf gel phytochemical content, antioxidant capacity and possible health benefits. J. Agric. Food. Chem. 55, 6891-6896.

Malamy, J., Carr, J.P., Klessig, D.F., and Raskin, I. 1990. Salicylic acid: A likely endogenous signal in the resistance response of tobacco to viral infection. Science $250,1002-1004$. 
Meyer, M.K.P. (Smith). 1996. Ornamental flowering plants, p. 641-650. In: Lindquist, E.E., Sabelis, M.W., Bruin, J. (Eds.). Eriophyoid mites: Their biology, natural enemies and control. Elsevier, Amsterdam.

Meyer, M.K.P. (Smith), and Craemer, C. 1999. Mites (Arachnida: Acari) as crop pests in southern Africa: An overview. Afr. Plant Prot. 5(1): 37-51.

Mithofer A., and Boland, W. 2008. Recognition of herbivory-associated molecular patterns. Plant Physiology 146, 825-831.

Monfreda, R., Nuzzaci, G., and de Lillo, E. 2007. Detection, extraction, and collection of eriophyoid mites. Zootaxa 1662, 35-43.

Moore, T. C. 1967. Kinetics of growth retardant and hormone interactions in affecting cucumber hypocotyl elongation. Plant Physiol. 42, 677-684.

Mumm, R. and Dicke, M. 2010. Variation in natural plant products and the attraction of bodyguards involved in indirect plant defense. Can. J. Zool. 88, 628-667.

Nault, L.R. 1997. Arthropod transmission of plant viruses: a new synthesis. Ann. Entomol. Soc. Am. 90, 521-541.

Nobel, P.S. 1976. Water relations and photosynthesis of a desert CAM plant Agave deserti. Plant Physiol. 58, 576-582.

Oldfield, G.N. 1996. Diversity and host plant specificity, p. 199-216. In: Lindquist, E.E., Sabelis, M.W., Bruin, J. (eds). Eriophyoid mites: Their biology, natural enemies and control. Elsevier, Amsterdam.

Oldfield, G.N. 2005. Biology of gall-inducing acari. In: Raman, A., Schaefer, C.W., Withers, T.M. (eds). Biology, ecology and evolution of gall-inducing arthropods. Science Publishers, Inc., Portland, OR.

Oldfield, G.N., and Proeseler, G. 1996. Eriophyoid mites as vectors of plant pathogens, p. 259-275. In: Lindquist, E.E., Sabelis, M.W., Bruin, J. (eds). Eriophyoid mites: Their biology, natural enemies and control. Elsevier, Amsterdam.

Ozawa, R., Shiojiri, K., Sabelis, M.W., and Takabayashi, J. 2008. Maize plants sprayed with either jasmonic acid or its precursor, methyl linolenate, attract armyworm parasitoids, but the composition of attractants differs. Entomol. Exp. Appl. 129, 189-199.

Petanović, R., and Kielkiewicz, M. 2010. Plant-eriophyoid mite interactions: Cellular biochemistry and metabolic responses induced in mite-injured plants. Part I. Exp. App. Acarol. 51, 61-80. 
Pieterse, C.M.J., Leon-Reyes, A., Van der Ent, S., and Van Wees, S.C.M. 2009.

Networking by small-molecule hormones in plant immunity. Nat. Chem. Biol. 5, 308-316.

Qin, G., Gu, H., Zhao, Y., Ma, Z., Shi, G., Yang, Y., Pichersky, E., Chen, H., Liu, M., Chen, Z., and Qu, L.J. 2005. An indole-3-acetic acid carboxyl methyltransferase regulates Arabidopsis leaf development. Plant Cell 17, 2693-2704.

Rodríguez-Garcia, R., Jasso de Rodríguez, D., Gil-Marín, J.A., Angulo-Sánchez, J.L., Lira-Saldívar, R.H. 2007. Growth, stomatal resistance, and transpiration of Aloe vera under different soil water potentials. Ind. Crops Prod. 25, 123-128.

Schäfer, M., Fischer, C., Meldau, S., Seebald, E., Oelmüller, R., and Baldwin, I.T. 2011. Lipase activity in insect oral secretions mediates defense responses in Arabidopsis. Plant Physiol. 156, 1520-1534.

Schmelz, E.A., Carroll, M.J., LeClere, S., Phipps, S.M., Meredith, J., Chourey, P.S., Alborn, H.T., and Teal, P.E.A. 2006. Fragments of ATP synthase mediate plant perception of insect attack. Proc. Natl. Acad. Sci., USA 103, 8894-8899.

Schmelz, E.A., Engelberth, J., Alborn, H.T., Tumlinson, J.H. III, Teal, P.E.A. 2009. Phytohormone-based activity mapping of insect herbivore-produced elicitors. Proc. Natl. Acad. Sci. USA 106, 653-657.

Shalmashi, A., and Ellassi, A. 2008. Solubility of salicylic acid in water, ethanol, carbon tetrachloride, ethyl acetate, and xylene. J. Chem. Eng. Data 53, 199-200.

Sheteawi, A.S., Tawfik, K.M., and Abd El-Gawad, Z. 2001. Water relations, transpiration rate, stomatal behavior and leaf sap $\mathrm{pH}$ of Aloe vera and Aloe eru. Egypt. J. Biol. 3, 140-148.

Simonsen, S.M., Sando, L., Ireland, D.C., Colgrave, M.L., Bharathi, R., Goransson, U., and Craik, D.J. 2005. A continent of plant defense peptide diversity: Cyclotides in Australian Hybanthus (Violaceae). Plant Cell 17, 3176-3189.

Sklar, J. 2012. March 9, 2012. Statistics Department, California Polytechnic State University, San Luis Obispo, 1 Grand Ave., San Luis Obispo, Ca. 93407.

Skoracka, A., Smith, L., Oldfield, G., Cristofaro, M., and Amrine, J.W. 2010. Host-plant specificity and specialization in eriophyoid mites and their importance for the use of eriophyoid mites as biocontrol agents of weeds. Exp. Appl. Acarol. 51, 93-113.

Takahashi, H., Kanayama, Y., Zheng, M.S., Kusano, T., Hase, S., Ikegami M., and Shah, J. 2004. Antagonistic interactions between the SA and JA signaling pathways in Arabidopsis modulate expression of defense genes and gene-for-gene resistance to cucumber mosaic virus. Plant Cell Physiol. 45, 803-809. 
Treutlein, J., Smith, G.F, van Wyk, B.-E, and Wink, M. 2003. Phylogenetic relationships in the Asphodelaceae (subfamily Alooideae) inferred from chloroplast DNA sequences ( $r b c L, m a t K)$ and from genomic fingerprinting (ISSR). Taxon 52, 193-207.

Truman, W., Bennett, M.H., Kubigsteltig, I., Turnbull, C., and Grant, M. 2007. Arabidopsis systemic immunity uses conserved defense signaling pathways and is mediated by jasmonates. Proc. Nat. Acad. Sci. 104, 1075-1080.

Wakabayashi, K., Sakurai, N., and Kuraishi, S. 1991. Differential effect of auxin on molecular weight distributions of xyloglucans in cell walls of outer and inner tissues from segments of dark grown squash (Cucurbita maxima Duch.) hypocotyls. Plant Physiol. 95, 1070-1076.

Wasternack, C. 2007. Jasmonates: An update on biosynthesis, signal transduction and action in plant stress response, growth and development. Ann. Bot. (Lond.) 100, 681-697.

Winde, I. and Wittstock, U. 2011. Insect herbivore counter adaptations to the plant glucosinolate-myrosinase system. Phytochemistry 72, 1566-1575.

Wu, J.Q., and Baldwin, I.T. 2009. Herbivory-induced signaling in plants: Perception and action. Plant Cell and Environment, 32, 1161-1174.

Yamaguchi Y., and Huffaker A. 2011. Endogenous peptide elicitors in higher plants. Curr. Opin. Plant Biol. 14, 351-357.

Yang, Y., Qi, M., and Mei, C. 2004. Endogenous salicylic acid protects rice plants from oxidative damage caused by aging as well as biotic and abiotic stress. Plant J. 40, 909-919.

Zarate, S.I., Kempema, L.A., and Walling, L.L. 2007. Silverleaf whitefly induces salicylic acid defenses and suppresses effectual jasmonic acid defenses. Plant Physiol. 143, 866-875.

Zipfel, C. 2008. Pattern-recognition receptors in plant innate immunity. Curr. Opin. Immunol. 20, 10-16.

Zipfel, C., Kunze, G., Chinchilla, D., Caniard, A., Jones, J.D.G., Boller, T., and Felix, G. 2006. Perception of the bacterial PAMP EF-Tu by the receptor EFR restricts Agrobacterium-mediated transformation. Cell 125, 749-760. 